\title{
Quantifying transport into the lowermost stratosphere using simultaneous in-situ measurements of $\mathrm{SF}_{6}$ and $\mathrm{CO}_{2}$
}

\author{
H. Bönisch ${ }^{1}$, A. Engel ${ }^{1}$, J. Curtius ${ }^{1}$, Th. Birner ${ }^{2}$, and P. Hoor ${ }^{3}$ \\ ${ }^{1}$ Institute for Atmospheric and Environmental Sciences, Goethe University Frankfurt, Frankfurt am Main, Germany \\ ${ }^{2}$ Department of Atmospheric Science, Colorado State University, Fort Collins, CO, USA \\ ${ }^{3}$ Institute for Atmospheric Physics, University of Mainz, Germany \\ Received: 7 October 2008 - Published in Atmos. Chem. Phys. Discuss.: 19 December 2008 \\ Revised: 26 June 2009 - Accepted: 5 August 2009 - Published: 19 August 2009
}

\begin{abstract}
The seasonality of transport and mixing of air into the lowermost stratosphere (LMS) is studied using distributions of mean age of air and a mass balance approach, based on in-situ observations of $\mathrm{SF}_{6}$ and $\mathrm{CO}_{2}$ during the SPURT (Spurenstofftransport in der Tropopausenregion, trace gas transport in the tropopause region) aircraft campaigns. Combining the information of the mean age of air and the water vapour distributions we demonstrate that the tropospheric air transported into the LMS above the extratropical tropopause layer (ExTL) originates predominantly from the tropical tropopause layer (TTL). The concept of our mass balance is based on simultaneous measurements of the two passive tracers and the assumption that transport into the LMS can be described by age spectra which are superposition of two different modes. Based on this concept we conclude that the stratospheric influence on LMS composition is strongest in April with extreme values of the tropospheric fractions $\left(\alpha_{1}\right)$ below $20 \%$ and that the strongest tropospheric signatures are found in October with $\alpha_{1}$ greater than $80 \%$. Beyond the fractions, our mass balance concept allows us to calculate the associated transit times for transport of tropospheric air from the tropics into the LMS. The shortest transit times $(<0.3$ years) are derived for the summer, continuously increasing up to 0.8 years by the end of spring. These findings suggest that strong quasi-horizontal mixing across the weak subtropical jet from summer to mid of autumn and the considerably shorter residual transport time-scales within the lower branch of the Brewer-Dobson circulation in summer than in winter dominates the tropospheric influence in the LMS until the beginning of next year's summer.
\end{abstract}

Correspondence to: $\mathrm{H}$. Bönisch (boenisch@iau.uni-frankfurt.de)

\section{Introduction}

Nowadays the tropopause region is regarded as a key for understanding and predicting future photochemically and radiatively induced climate change. Changes in concentrations of radiatively active species in this region potentially have a strong impact on the radiation balance of the troposphere (e.g., Lacis et al., 1990; Forster and Shine, 1997). It is well known that the large-scale stratospheric mean meridional circulation driven by wave dissipation governs the net upwelling flux from the troposphere to the stratosphere in the tropics and the net downwelling flux from the stratosphere to the troposphere in the extratropics (Haynes et al., 1991; Holton et al., 1995). However, it is not only important to understand net fluxes across the tropopause but also the exchange rates in order to improve the understanding of the tropospheric impact on the chemical composition of the stratosphere, e.g. the dehydration of the stratosphere (Fueglistaler et al., 2004, 2005) or the role of very short lived halogenated species (VSLS) on ozone destruction (Dvortsov et al., 1999; Ko et al., 2003; Levine et al., 2007; Law and Sturges, 2007; Olson et al., 2008; Laube et al., 2008). The net stratospheretroposphere exchange (STE) from a climatology point of view, i.e. the net irreversible mixing across the tropopause, is the combined effect of two way transport, i.e. troposphere-tostratosphere transport (TST) and stratosphere-to-troposphere transport (STT), eddy diffusion and finally molecular diffusion.

In this study we focus on the lowermost stratosphere (LMS) which is bounded by the $380 \mathrm{~K}$ isentrope and the extratropical tropopause. The entire LMS contains air of recent tropospheric origin (e.g. Ray et al., 1999). In-situ measurements of different trace gases such as ozone, carbon monoxide and water vapour revealed that a layer immediately above the extratropical tropopause shows chemical characteristics

Published by Copernicus Publications on behalf of the European Geosciences Union. 
which are intermediate between the extratropical troposphere and the stratosphere (Fischer et al., 2000; Hoor et al., 2002, 2004; Pan et al., 2004; Krebsbach et al., 2006; Brioude et al., 2008). This layer has been referred to as the extratropical tropopause layer (ExTL) (Hoor et al. 2004; Pan et al., 2004). The ExTL can be regarded as a transition zone between both reservoirs with transport time scales ranging from hours to several days and with a vertical extent of typically $20 \mathrm{~K}$ or $2 \mathrm{~km}$ (Hoor et al., 2004; Pan et al., 2004).

The LMS in the vicinity of the local tropopause is also distinct in terms of its thermal stratification: on average the temperature profile exhibits a strong inversion at the local tropopause with strongly increasing temperature (i.e. high static stability) within the so-called tropopause inversion layer (TIL) (Birner, 2006). This TIL roughly corresponds to the ExTL in terms of location and vertical extent and recent studies have suggested a radiative link between the TIL and the specific water vapour and ozone distributions within the ExTL (Randel et al., 2007; Hegglin et al., 2009). Strong stratification and a sharp local tropopause associated with the TIL suggest that the air above this layer is vertically strongly isolated from the extratropical upper troposphere below.

From the chemical composition of the LMS it has been concluded that a substantial fraction of air above the ExTL has been mixed in to higher latitudes quasi-horizontally from the upper tropical troposphere (e.g. Dessler et al., 1995; Hintsa et al., 1998; Ray et al., 1999; Pan et al., 2000; Hoor et al., 2004, 2005; Hegglin et al., 2006; Sawa et al., 2008). Model studies indicate that bidirectional cross-tropopause transport at potential temperature levels between 340 and $360 \mathrm{~K}$ in the vicinity of the subtropical jet is strongly inhibited in winter (Haynes and Shuckburgh, 2000), while substantial exchange occurs at these altitudes in summer (Chen, 1995; Berthet et al., 2007).

In this paper we use mean age of air derived from $\mathrm{SF}_{6}$ measurements for diagnosing the seasonality of tracer transport into the LMS. The term "tracer transport" will be used here to refer to the combined processes of transport by the residual (Brewer-Dobson) circulation in the Transformed Eulerian Mean (TEM) sense (Andrews et al., 1987) and quasihorizontal stirring by the eddies.

Furthermore, we present an approach to quantify tracer transport into the LMS above the ExTL. In this part the chemical composition is dominated by the relative strength of quasi-horizontal transport and mixing from the tropics into the extratropics and downward transport driven by the upper branch of the Brewer-Dobson circulation (e.g. Hoor et al., 2005; Sawa et al., 2008). The quasi-horizontal transport into the LMS can be further divided into two different pathways: 1) across the subtropical tropopause and 2) along the tropical tropopause with subsequent subsidence in the extratropics. This second pathway is referred to as the lower branch of the Brewer-Dobson circulation, which transports air quasihorizontally from the tropically controlled transition region above the tropical tropopause but below the lower edge of the tropical pipe to the extratropics (Rosenlof et al., 1997).

For this quantification of tracer transport into the LMS we set up a mass balance using simultaneous measurements of $\mathrm{SF}_{6}$ and $\mathrm{CO}_{2}$, which are passive tracers with different tropospheric characteristics. $\mathrm{CO}_{2}$ has a pronounced seasonal cycle in the troposphere superimposed on an average increase rate of about 1.6 ppmv year ${ }^{-1}$. In contrast, $\mathrm{SF}_{6}$ shows a secular increase from very low mixing ratios $<0.1 \mathrm{ppt}$ in the early 1960 s to more than $6 \mathrm{ppt}$ in global mean nowadays, without seasonal variations. The propagation of these different signals of both tracers into the stratosphere can be exploited to calculate the tropospheric fraction of an air parcel and its mean transit time from the troposphere into the LMS, as will be shown below. The seasonality and spatial distribution of mean transit times represent important new information that has not been derived previously in other mass balance studies of the LMS (e.g. Ray et al., 1999; Pan et al., 2000). This additional information about the transit time can also be used to link the results derived from trace gas measurements with the results derived from trajectory studies (e.g. Stohl, 2001, 2003; Wernli and Bourqui, 2002; Sprenger and Wernli, 2003; James et al., 2003a, b; Berthet et al., 2007).

\section{Data set}

The data set used for this study has been obtained during the SPURT project, which was part of the German AFO 2000 program. High quality measurements of a number of tracers with different chemical lifetimes were performed in the UT/LMS region covering a latitudinal range between $30^{\circ} \mathrm{N}$ and $80^{\circ} \mathrm{N}$ over Europe. Every season was probed twice during intensive campaigns over a period of 2 years. For a detailed analysis of the SPURT data coverage see Hoor et al. (2004). In total, 36 flights have been performed during SPURT. A detailed overview of the SPURT results, including technical details, is given by Engel et al. (2006a) and references therein.

The $\mathrm{CO}_{2}$ measurements have been performed with a modified Li-COR 6262 NDIR-instrument with a time resolution of $1 \mathrm{~Hz}$ and a total uncertainty better than 0.3 ppmv. Unfortunately, there are no $\mathrm{CO}_{2}$ data available for the SPURT campaign S8 in July 2003 (Gurk et al., 2008).

$\mathrm{SF}_{6}$ data are not available for some flights of the SPURT project due to instrumental problems. For this reason, we decided to derive $\mathrm{SF}_{6}$ from $\mathrm{N}_{2} \mathrm{O}$ observations, which were measured independently by in-situ gas chromatography with an electron capture detector (ECD) and by tuneable diode laser spectroscopy. As an example, Fig. 1 shows the observed linear $\mathrm{N}_{2} \mathrm{O} / \mathrm{SF}_{6}$ relationship in the UT/LMS during SPURT campaign S8 performed in July 2003. The $\mathrm{N}_{2} \mathrm{O}$-derived $\mathrm{SF}_{6}$ is based on the strict linear relationships between both tracers which were calculated separately for each deployment, i.e. within a maximum two days from the day of the respective 
flight (Boenisch et al., 2008). The relationships are strictly linear, given that the standard deviations from measured $\mathrm{SF}_{6}$ and those from $\mathrm{N}_{2} \mathrm{O}$-derived $\mathrm{SF}_{6}$ are equal to the statistical error given by the precision of both instruments. This approach has the advantage that the $\mathrm{N}_{2} \mathrm{O}$ measurements have a much higher time resolution (5 $\mathrm{s})$ and a slightly better precision $(\sim 1 \%)$ than the $\mathrm{SF}_{6}$ measurements $(\sim 1.5 \%$ with a time resolution of 60-90 s). However, we want to emphasize that this approach is only valid in the LMS and if the applied linear relation between $\mathrm{SF}_{6}$ and $\mathrm{N}_{2} \mathrm{O}$ has been observed in real-time, because the relation varies with season and time.

Beside $\mathrm{SF}_{6}$ and $\mathrm{CO}_{2}$, we also use the water vapour measurements of SPURT which have a $1 \mathrm{~Hz}$ time resolution, an overall accuracy of $6 \%$ and a precision of $0.15 \mathrm{ppmv}$ in the range from about $500 \mathrm{ppmv}$ to $1.0 \mathrm{ppmv}$ for measurements in the UTLS region (Krebsbach et al., 2006).

\section{Characterization of $\mathrm{SF}_{6}$ and $\mathrm{CO}_{2}$}

The tropospheric sources and sinks of both tracers, $\mathrm{SF}_{6}$ and $\mathrm{CO}_{2}$, are located exclusively on the Earth's surface, with the exception of a small source of $\mathrm{CO}_{2}$ from the oxidation of hydrocarbons in the atmosphere. $\mathrm{SF}_{6}$ has an atmospheric lifetime of about 3200 years (Ravishankara et al., 1993) with only anthropogenic sources in the troposphere and a sink in the mesosphere (Hall and Waugh, 1998; Reddmann et al., 2001). The NOAA-ESRL global flask network data shows that the mixing ratio of $\mathrm{SF}_{6}$ in the troposphere has grown with a nearly constant rate of about 0.2 ppt year $^{-1}$ since 1996. In the remote and free troposphere, the $\mathrm{SF}_{6}$ distribution shows no significant variability, but a meridional gradient due to the larger electrical power production in the Northern Hemisphere compared to the Southern Hemisphere (Ko et al., 1993; Maiss and Levin, 1994).

Similar to $\mathrm{SF}_{6}, \mathrm{CO}_{2}$ increases almost linearly in the atmosphere with an average growth rate of about 1.6 ppmv year $^{-1}$ over the last decades, due to anthropogenic emissions, mostly fossil fuel burning and deforestation. But in contrast to $\mathrm{SF}_{6}$, a seasonal cycle is superimposed on the long term increase of tropospheric $\mathrm{CO}_{2}$ mixing ratios. This seasonality is mainly driven by biogenic activity. The amplitude of the $\mathrm{CO}_{2}$ seasonal cycle in the troposphere is much larger in the Northern (more than \pm 10 ppmv in high latitudes) than in the Southern Hemisphere (less than \pm 1 ppmv in high latitudes). The amplitude of about \pm 3 ppmv particularly in the tropical lower troposphere is twice as large as the averaged yearly growth rate. Thus, the tropospheric seasonal cycle is a dominant feature which propagates upwards through the tropopause into the lower stratosphere (LS) and spreads out meridionally, as shown by e.g., Boering et al. (1994, 1996), Strahan et al. (1998) and Andrews et al. (1999, 2001).

\section{Mean age of air}

Transport in the atmosphere is the result of the complex action of time-dependent and often highly turbulent flow. A useful diagnostic that summarizes the rate at which fluid elements are transported from some region to a point via a multiplicity of pathways and mechanisms is the transit time distribution (TTD) which is usually called the age spectrum in the context of stratospheric transport. The general advantage of this diagnostic is that "age of air" is species-independent and encompasses both the residual transport and the (quasihorizontal) mixing. Transit time distributions have first been discussed and applied to stratospheric transport analysis by Kida (1983) and by Hall and Plumb (1994), further referred to as HP94.

The age spectrum is a diagnostic of the flow, independent of the distribution of any tracer. It characterizes the "transport history" of the fluid from a region $\Omega$ to a point $r$. The age spectrum $(\mathrm{G})$ is the probability density function of $\Omega$-to-r transit times. In mathematical terms, $\mathrm{G}$ is the Green's function for the differential operator governing the transport of tracer. The age spectrum is typically a rather broad distribution, reflecting the multiplicity of available pathways to the fluid from the entrance region or control surface $\Omega$, normally the tropical tropopause, to a point $r$ in the stratosphere. HP94 defined the age spectrum as the distribution of times since the fluid elements constituting a given stratospheric air parcel had last contact with the troposphere. The first moment of the distribution is defined as the mean age $\Gamma$ (HP94). Following this definition, the mean age of air at a point in the stratosphere is the mean transit time since the air there was last in the troposphere. The age spectrum concept proved to be a useful tool for interpreting tracer observations in the stratosphere (e.g. Waugh and Hall, 2002, and references within). Although G itself is not directly observable, its first moment, $\Gamma$ can be inferred from measurements of appropriate tracers (e.g., Schmidt and Khedim, 1991; Elkins et al., 1996; Boering et al., 1996).

\subsection{Deriving mean age from long-lived tracers}

Long-lived or ideally inert (also called passive) tracers which have negligible stratospheric sinks or sources and show monotonically increasing or decreasing mixing ratios $\chi(\Omega, t)$ with time in the troposphere, are a class of tracers that is suited to derive stratospheric mean age. Here $\chi(\Omega, t)$ is the mixing ratio at the ground surface, $\Omega$, controlling the input into the stratosphere at a given time $t$. Note that we have chosen to use the ground surface instead of the tropopause as the control level, simply because of the availability of a network of continuous $\mathrm{SF}_{6}$ and $\mathrm{CO}_{2}$ measurements. In order to constrain the tropical time series, we use the data from NOAA-ESRL HATS flask sampling program (2007) for $\mathrm{SF}_{6}$ and the data from GLOBALVIEW- $\mathrm{CO}_{2}$ (2007) for $\mathrm{CO}_{2}$. 


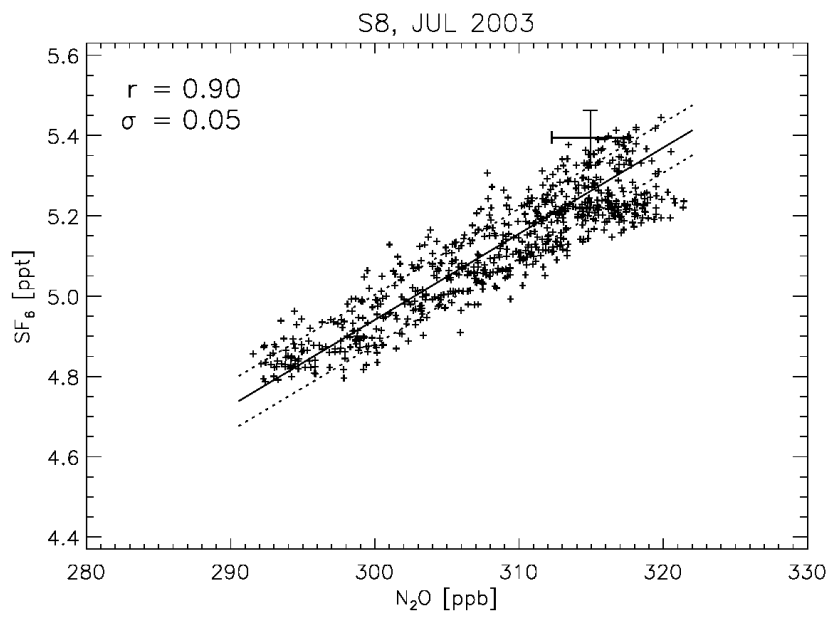

Fig. 1. $\mathrm{N}_{2} \mathrm{O} / \mathrm{SF}_{6}$ correlation observed during the SPURT campaign S8 in July 2003. The solid line indicates the linear regression to the data with corresponding correlation coefficient $(r)$ and the dashed line marks the standard deviation $(\sigma)$.

Both tracers, $\mathrm{SF}_{6}$ and $\mathrm{CO}_{2}$ which have been measured simultaneously during the SPURT project, meet the criteria of inertness in the stratosphere and monotonic growth in the troposphere in first approximation, but not exactly. In the lower stratosphere, the impact of the tropospheric $\mathrm{CO}_{2}$ seasonal cycle interferes with the mean age calculation (e.g. Boering et al., 1996). On the other hand, $\mathrm{SF}_{6}$ has a mesospheric sink, so that the criterion of inertness is violated in the polar vortices regions, where mesospheric air is descending back into the stratosphere (e.g. Strunk et al., 1998; Reddmann et al., 2001; Ray et al., 2002; Curtius et al., 2005; Engel et al., 2006b). Despite these facts, particularly in the LMS mean age can be determined solely from $\mathrm{SF}_{6}$, where $\mathrm{CO}_{2}$ is influenced by the seasonal cycle.

For these reasons, we use only $\mathrm{SF}_{6}$ to derive the mean age in the LMS. We use variable fit intervals to the tropospheric reference data (shorter fits for younger mean ages) and a parameterization of the age spectrum as a function of the mean age. This approach is necessary in order to take into account non-linearity in the atmospheric growth rates. This two step method that we applied here for stratospheric mean age of air calculation from $\mathrm{SF}_{6}$ observation is explained in detail by Engel et al. (2006b).

\subsection{Mean age distribution in the LMS}

Figure 2 shows mean age $\Gamma_{\mathrm{SF} 6}$ derived from SPURT $\mathrm{SF}_{6} \mathrm{ob}-$ servations in an equivalent latitude $\varphi_{e}$ versus potential temperature $\theta$ coordinate system. The advantage of such a coordinate system in representing trace gas distributions in the LMS is that a substantial amount of scatter in the observations can be removed (e.g. Hoor et al., 2004; Hegglin et al., 2004). This is due to the fact that the $\varphi_{e}-\theta$-coordinate system accounts for adiabatic air parcel displacements, e.g. the influence of transient (and largely reversible) north-south excursions of air parcels associated with dynamical features like Rossby waves, which significantly contribute to the variability in geographical space.

A close look at Fig. 2 reveals that negative values for $\Gamma_{\mathrm{SF} 6}$ are derived mainly below 4 pvu but in summer and autumn sometimes even up to the level of $6 \mathrm{pvu}$. During those occasions air from the Northern Hemisphere extratropical troposphere which contains higher mixing ratios of $\mathrm{SF}_{6}$ than in the tropics influences the composition of the LMS resulting in negative mean age values. Strictly, the term mean age is thus not correct in the LMS where it is affected by extratropical upper tropospheric air rather than the tropics, which acts as the control surface for the mean age calculation. However, we did not remove these data, because they nicely indicate the area and the extent where extratropical stratosphere-troposphere exchange predominantly influences the LMS. The thickness of the layer in potential temperature coordinates, which exhibits negative mean ages in the LMS, varies with season spanning a larger $\theta$-range during summer and autumn than in winter and spring. Its location and seasonality corresponds approximately with the ExTL described by Hoor et al. (2004) using $\mathrm{CO}-\mathrm{O}_{3}$ correlations and the TIL described by Birner et al. (2006) using highly resolved radiosonde temperature profiles.

In the LMS, the oldest air of up to 3 years was observed during April (see Fig. 2). During October, the youngest air with mean ages below 1 year was encountered throughout the LMS. Obviously, the mean age undergoes a seasonal cycle in the Northern Hemispheric LMS - increasing mean ages from October to April and decreasing mean ages from April to October. This cycle is phase shifted by about 3 month with respect to the seasonality of the downward mass flux from the overworld through the $380 \mathrm{~K}$ isentrope into the LMS which shows a maximum in December/January (Appenzeller et al., 1996). This illustrates that the mean age distribution in the LMS is not entirely driven by the strength of downward transport, but also depends on the isolation of the LMS from the troposphere. Thus, the mean age distribution in the LMS above the ExTL is controlled by the relative strength of the combination of quasi-horizontal mixing of young air from the tropics into the extratropics across the subtropical jet and the residual horizontal transport in the tropically controlled transition region just above the tropical tropopause (Rosenlof et al., 1997), versus the residual downward transport in the lower stratosphere. Different to the region above, the formation of the ExTL is dominated by rather localised TST-processes (e.g. Dessler et al., 1995; Hoor et al., 2002) whereby irreversible cross-tropopause transport near the polar jet also plays an important role (e.g. Fischer et al., 2000).

Figure 3 shows the water vapour distributions in the LMS in summer and autumn derived from the SPURT data set (Krebsbach et al., 2006) depicted in the same coordinate system as used for mean age in Fig. 2. Interestingly, the LMS is much drier during autumn when also the youngest air is 


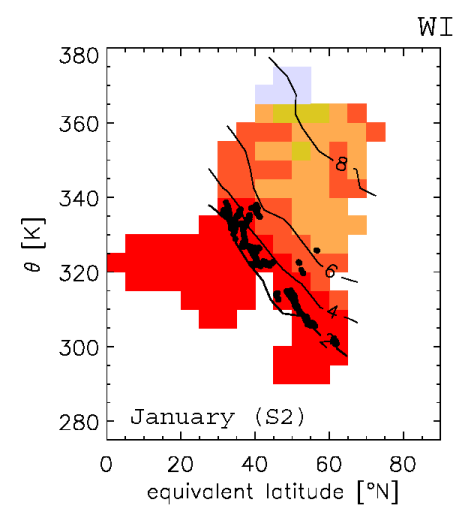

WINTER

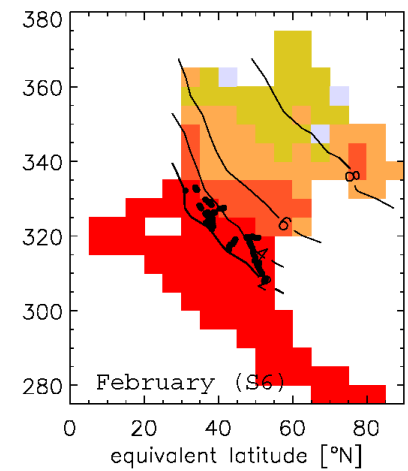

SUMMER
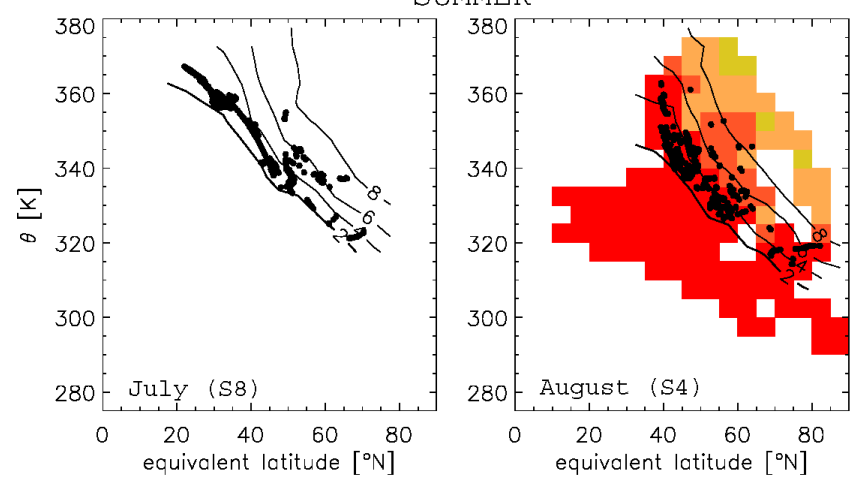
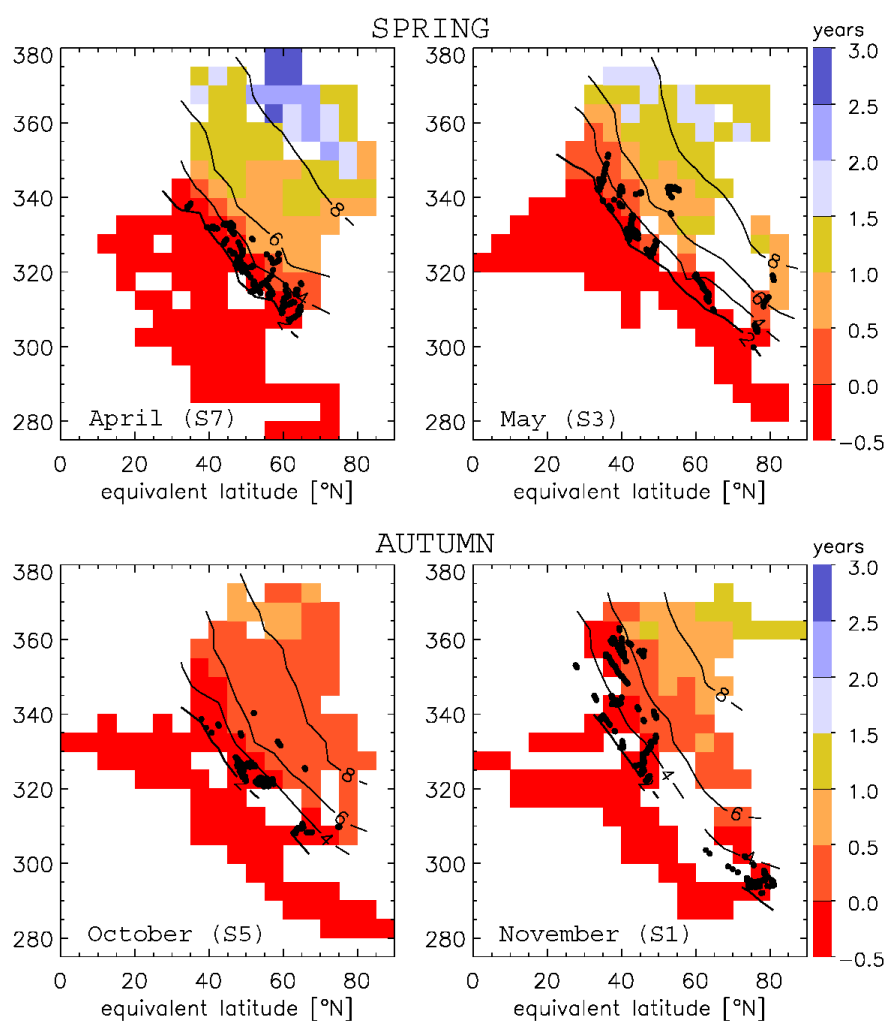

AUTUMN

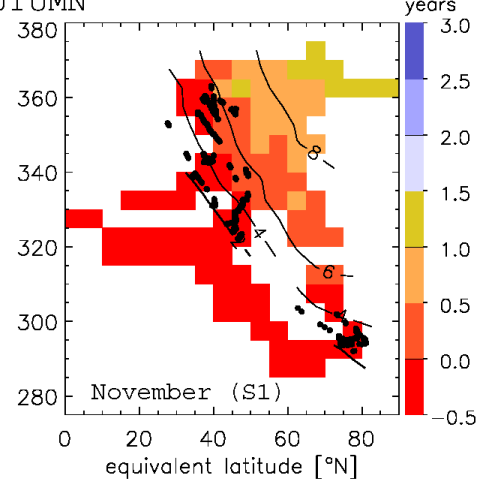

Fig. 2. Seasonal variation of the mean age distributions $\Gamma_{\mathrm{SF} 6}$ in the LMS. The data are binned according to $\varphi_{e}\left(5^{\circ} \mathrm{N}\right)$ and $\theta(5 \mathrm{~K})$, in order to remove short term atmospheric variability. The solid lines indicate the PV-isolines and the dots flag TST-events calculated from 10-day backward trajectories by applying the time criterion of Wernli and Bourqui (2002).

observed than during summer. This indicates that the LMS must be flushed with very dry tropospheric air $(<5 \mathrm{ppm})$ over the course of summer till autumn. The dryness of this young air implies that these air masses have been transported and mixed quasi-horizontally from the upper tropical tropopause layer (TTL) or from the lowest tropical stratosphere into the LMS. This is consistent with the shallow residual circulation during summer and autumn which provides a quasi-horizontal residual transport pathway between the tropics and the extratropics. Potential downward transport from higher altitudes, which would also result in low water vapour, is strongly reduced during summer and autumn and can be excluded due to the fact that the mean age is on the order of only 0.5 years during that time. A stronger contribution of (sub-) tropical air due to a decreased barrier against quasi-horizontal tracer transport at the subtropical jet during summer is also consistent with other observations (Hoor et al., 2005; Krebsbach et al., 2006; Sawa et al., 2008) and conclusions drawn by Chen (1995) based on model simulations, by Haynes and Shuckburgh (2000) based on the concept of effective diffusivity or by Sprenger and Wernli (2003) based on trajectory calculations.

\section{Mass balance}

In order to derive more quantitative information on the air mass origin in the LMS, we developed a method that allows us to calculate a mass balance for the LMS using simultaneous measurements of $\mathrm{SF}_{6}$ and $\mathrm{CO}_{2}$. This mass balance is based on the assumption that the distributions of $\mathrm{SF}_{6}$ and $\mathrm{CO}_{2}$ in the extratropical lower stratosphere can be described by age spectra which are superimpositions of two different modes as suggested by Andrews et al. (2001). We avoid the term bimodal because this implies two distinct maxima of the distribution. The latter is a special case of a superposition of two modes and it is also not a prerequisite for our mass balance study.

\subsection{Conceptual approach}

The concept of our mass balance for the LMS is shown schematically in Fig. 4. The mixing ratio of passive tracers in an air parcel located in the LMS can be described by a mixture of two major fractions. The first fraction $\left(\alpha_{1}\right)$ represents air which was transported along relatively fast pathways (magenta arrows in Fig. 4) which are associated with extratropical STE as well as tracer transport from the TTL into the extratropics. We include also air masses that have crossed 

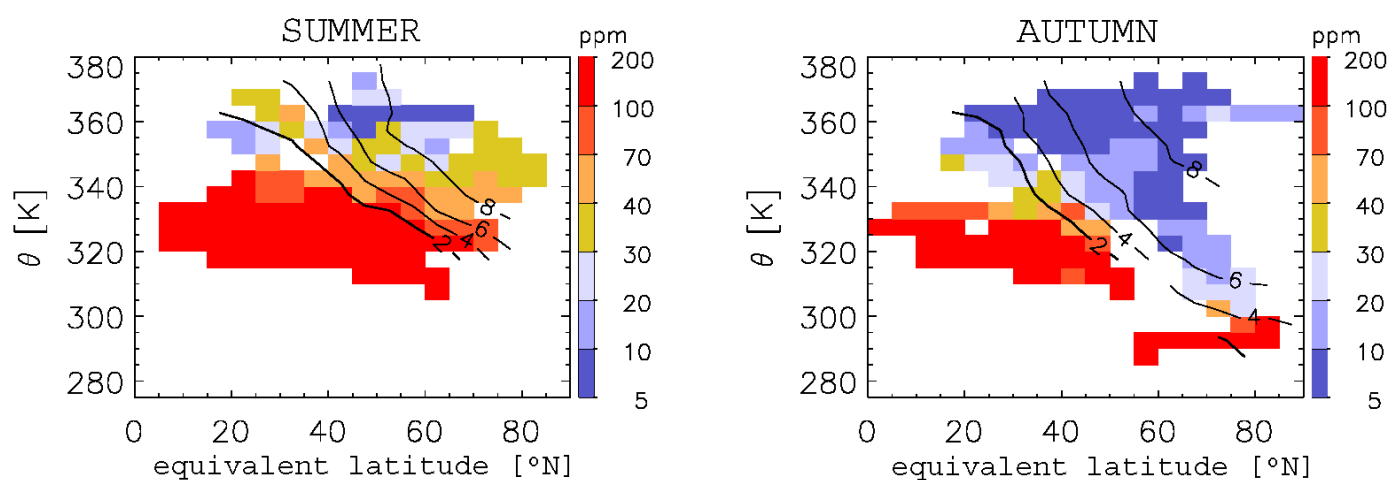

Fig. 3. Distribution of water vapour in the LMS during summer and autumn derived from SPURT data set. The data are binned according to $\varphi_{e}\left(5^{\circ} \mathrm{N}\right)$ and $\theta(5 \mathrm{~K})$, in order to remove short term atmospheric variability. The solid lines indicate the PV-isolines.

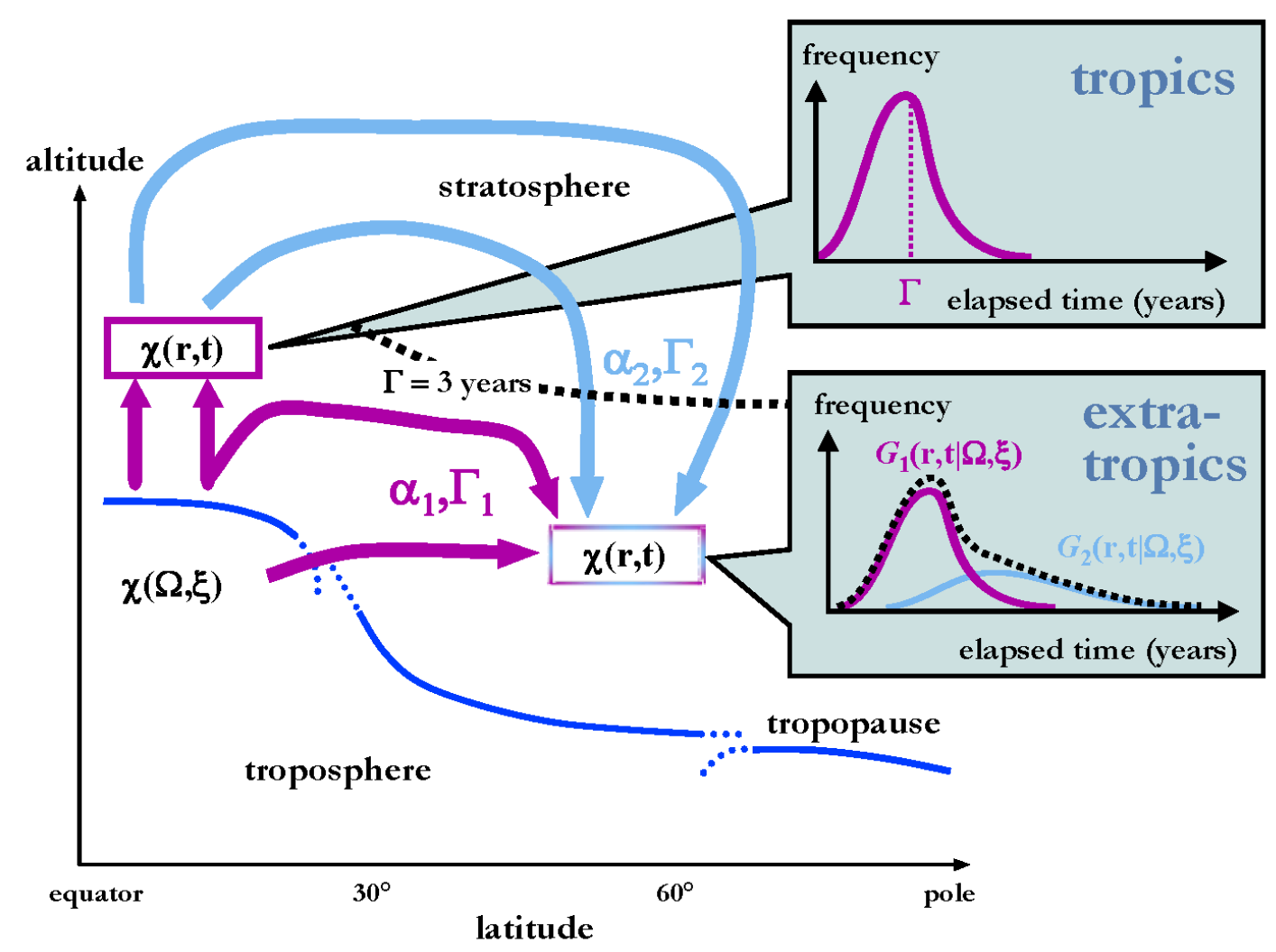

Fig. 4. Schematic representation of the mass balance concept for the lower stratosphere. The arrows symbolise different stratospheric transport pathways. The boxes indicate a typical tropical (magenta) and extratropical (blue and magenta) lower stratospheric air parcel for which the assumed age spectra or transit time distributions are shown. A detailed description is given in the text.

the tropical tropopause region spreading to the lower stratosphere of higher latitudes between $380 \mathrm{~K}<\theta<450 \mathrm{~K}$ which has been referred to as the "tropical controlled transition region" (Rosenlof et al., 1997). This latter transport pathway is associated with the lower branch of the Brewer-Dobson circulation as evident in the strong poleward flow seen in TEM circulation (Shepherd, 2007, and references within). Boering et al. (1996) derived a transport timescale of about 2 months for transport from the tropics to the extratropics in this region.

The second fraction $\left(\alpha_{2}\right)$ in our mass balance approach describes the amount of air transported along the slower pathways (light blue arrows) which is associated with the deeper branch of the Brewer-Dobson circulation reaching up to the mesosphere and that mainly drives the downward transport from the overworld into the LMS. In the following, we name 
for simplification $\alpha_{1}$ the tropospheric fraction and $\alpha_{2}$ the stratospheric fraction, in order to reflect the origin of the air masses.

In a mathematical way, the concept explained above can be translated into the following basic equation for the mass balance by describing the mixing ratio of a passive tracer as the superposition of two monomodal age spectra, each folded with the respective tropospheric input function, according to the concept of HP94:

$$
\begin{aligned}
\chi(r, t)= & \alpha_{1} \underbrace{\int_{0}^{\infty} \underbrace{\chi\left(\Omega_{1}, \varepsilon\right)}_{\chi_{1, i n}} \cdot \underbrace{G\left(\Gamma_{1}, \Delta_{1}, \varepsilon\right)}_{G_{1}} d \varepsilon}_{\chi_{1}\left(\Omega_{1}, \Gamma_{1}, \Delta_{1}\right)} \\
& +\alpha_{2} \underbrace{\int_{0}^{\infty} \underbrace{\chi\left(\Omega_{2}, \varepsilon\right)}_{\chi_{2, i n}} \cdot \underbrace{G\left(\Gamma_{2}, \Delta_{2}, \varepsilon\right)}_{G_{2}} d \varepsilon}_{\chi_{2}\left(\Omega_{2}, \Gamma_{2}, \Delta_{2}\right)}
\end{aligned}
$$

Subject to the constraints

$\alpha_{1}+\alpha_{2}=1$

$$
\int_{0}^{\infty} G_{1} d \varepsilon=\int_{0}^{\infty} G_{2} d \varepsilon=1
$$

Here, $\chi(r, t)$ is the mixing ratio of a passive tracer at a given location $r$ and time $t$ in the stratosphere, whereby the entry functions $\chi_{1, \text { in }}$ and $\chi_{2, \text { in }}$ specify the time series of the tracer mixing ratio at the entrance regions $\Omega_{1}$ and $\Omega_{2}$ into the stratosphere during the elapsed time $\varepsilon=t-t_{0}$. The two modes $G_{1}$ and $G_{2}$ of the age spectrum represent the transport time distributions along the faster (magenta, $\mathrm{G}_{1}$ ) and slower (light blue, $\mathrm{G}_{2}$ ) transport pathways into the LMS shown in Fig. 4 and the superposition of both describes the entirety of all transport pathways. The dimensionless parameters $\alpha_{1}$ and $\alpha_{2}$ correspond to the fraction of the air transported along the different pathways into the LMS. The latter is a consequence of the constraints which are associated to mass conservation (2) and standardisation (3). For our purpose, the applied age spectra $\mathrm{G}$ for mass balance calculation are defined in a convenient way as an Inverse Gaussian Distribution (IG) in terms of the mean age $\Gamma$ and the width $\Delta$, used in many different fields (e.g. Chhikara and Folks, 1989; Seshadri, 1999):

$$
G(t)=\sqrt{\frac{\Gamma^{3}}{4 \pi \Delta^{2} t^{3}}} \cdot \exp \left(\frac{\Gamma(t-\Gamma)^{2}}{4 \Delta^{2} t}\right) .
$$

The basic mass balance Eq. (1) given above is of general nature. This means that it describes a property (the "transport history") of each stratospheric air parcel. For this reason, the equations above must be valid for all passive tracers measured at the same time in the stratosphere. In our case, we will use simultaneous measurements of the tracers $\mathrm{SF}_{6}$ and $\mathrm{CO}_{2}$, which are available in the SPURT data set, in order to constrain the equation and to study transport into the LMS.

For this specific combination of tracers, we restrict the mass balance study to the stratospherically dominated part of the LMS above the ExTL or TIL respectively. In this region, the propagation of the tropospheric $\mathrm{CO}_{2}$ seasonal cycle is still detectable. Boering et al. (1996) and Strahan et al. (1998) demonstrated that the seasonal cycle affects the extratropical stratosphere below $\sim 440 \mathrm{~K}$ or $\mathrm{N}_{2} \mathrm{O}$ mixing ratios greater than $\sim 250 \mathrm{ppb}$. The latter corresponds to a stratospheric mean age of about $\Gamma=3$ years (Engel et al., 2002). If the mean age is greater than 3 years, the age spectrum is so broad that the tropospheric $\mathrm{CO}_{2}$ seasonal cycle is smeared out. Hence, the combination of both tracers does not provide additional information about the age spectrum of an air parcel, as the Eqs. (1) for both tracers become linear dependent for $\Gamma>3$ years.

The restriction discussed above is introduced to the mass balance equation as an additional constraint in the way that the mean age $\Gamma_{2}$ of the mode $G_{2}$, mapping the slower transport branch overturning the whole stratosphere, is fixed to a value of 3 years (Fig. 4: black dotted line). This mean age isoline represents the upper boundary of our mass balance study for the lower stratosphere. In accordance with the concept of HP94, we apply the parameterisation that the width of the age spectrum $\Delta$ is a function of mean age

$\frac{\Delta^{2}}{\Gamma}=$ constant $=C$,

whereby we use the constant $C_{2}=0.7$ years as suggested by HP94 and applied by Engel et al. (2002) for the age spectra representing the deeper branch of the Brewer-Dobson circulation. An air parcel with a mean age of 3 years is certainly located in the overworld which the air can only reach by transport across the tropical tropopause (Holton et al., 1995). For this reason, we use the time series of $\mathrm{SF}_{6}$ and $\mathrm{CO}_{2}$ in the tropical troposphere between $10^{\circ} \mathrm{S}$ and $10^{\circ} \mathrm{N}$ as the stratospheric entry function $\chi_{2, i n}$. As explained above, the ground surface instead of the tropopause was chosen as control level $\Omega_{2}$, simply because of the availability of $\mathrm{SF}_{6}$ and $\mathrm{CO}_{2}$ measurements there. The consequence of this approach is that the mean age includes the average transit time from the ground surface to the tropopause.

The mode $G_{1}$ represents not only the transport pathways across the tropical tropopause but also transport pathways across the sub- and extratropical tropopause. In order to describe these additional pathways into the Northern Hemisphere LMS, the entry function $\chi_{1, \text { in }}$ must be different from $\chi_{2, \text { in }}$. Due to the strong meridional gradient of $\mathrm{SF}_{6}$ and $\mathrm{CO}_{2}$ in the troposphere, we restrict the mass balance in the LMS to the region above the ExTL, where TST across the extratropical tropopause can be excluded as far as possible (Hoor et al., 2004). We chose a criterion of mean age $\Gamma_{\mathrm{SF} 6}>0.3$ years for this region (see Sect. 3.2). This also marks the lower 
boundary for our mass balance study. Due to this restriction, the control surface $\Omega_{1}$ should be the tropical and subtropical tropopause only and the entry functions $\chi_{1, \text { in }}$ for $\mathrm{SF}_{6}$ and $\mathrm{CO}_{2}$ should be the time series of both tracers at this control surface. As for the other entry function $\chi_{2}$,in, there are no sufficient data sets available for the description of $\chi_{1, \text { in }}$ at the tropopause. Hence same as for $\Omega_{2}$, the earth surface instead of the tropopause has to serve as control surface $\Omega_{1}$. In order to allow for the additional subtropical transport pathways of the mode $\mathrm{G}_{1}$ we decided to use the average tropospheric time series of both tracers between $0^{\circ} \mathrm{N}$ and $20^{\circ} \mathrm{N}$. Our choice of this threshold is motivated by the work of Berthet et al. (2007). They demonstrated that nearly all 30day backward trajectories started in the LMS above the ExTL (at the $365 \mathrm{~K}$ level) are leaving the boundary layer $(z<1 \mathrm{~km})$ between $0^{\circ} \mathrm{N}$ and $20^{\circ} \mathrm{N}$.

Using Eq. (2), it is possible to substitute the stratospheric fraction $\alpha_{2}$ in the basic mass balance Eq. (1). Hence, we can formulate the Eq. (6) for the tropospheric fraction $\alpha_{1}$ :

$\alpha_{1}=\frac{\chi(r, t)-\chi_{2}\left(\Omega_{2}, \Gamma_{2}, \Delta_{2}\right)}{\chi_{1}\left(\Omega_{1}, \Gamma_{1}, \Delta_{1}\right)-\chi_{2}\left(\Omega_{2}, \Gamma_{2}, \Delta_{2}\right)}$

Taking into account all constraints for $\Omega_{1}, \Omega_{2}, \Gamma_{2}$ and $\Delta_{2}$ introduced above only two unknown parameters in Eq. (6) are left that have to be determined. These are the mean age or mean transit time $\Gamma_{1}$ representing the fast transport branch and the constant $C_{1}$ defining the ratio of the width of the mode $\mathrm{G}_{1}$ with respect to $\Gamma_{1}$, as shown in Eq. (5). The following system of Eqs. (7) has to be solved numerically to derive the tropospheric fraction $\alpha_{1}$ from simultaneous measurements of $\mathrm{SF}_{6}$ and $\mathrm{CO}_{2}$ obtained during the SPURT campaigns

$$
\begin{aligned}
\alpha_{1, \mathrm{SF} 6} & =\frac{\chi_{\mathrm{SF} 6}(r, t)-\chi_{2, \mathrm{SF} 6}}{\chi_{1, \mathrm{SF} 6}\left(\Gamma_{1}, \Delta_{1}\right)-\chi_{2, \mathrm{SF} 6}} \\
\alpha_{1, \mathrm{CO} 2} & =\frac{\chi_{\mathrm{CO} 2}(r, t)-\chi_{2, \mathrm{CO} 2}}{\chi_{1, \mathrm{CO} 2}\left(\Gamma_{1}, \Delta_{1}\right)-\chi_{2, \mathrm{CO} 2}}
\end{aligned}
$$

subject to the constraint

$\alpha_{1, \mathrm{SF} 6}=\alpha_{1, \mathrm{CO} 2}$.

Equation (8) is the direct consequence of the fact that an age spectrum is a transit time distribution of all $\Omega$-to-r pathways which is characteristic for a specific air parcel in the stratosphere but not for a distinct passive tracer. The tropospheric fraction $\alpha_{1}$ can be determined from Eqs. (7) and (8) numerically by variation of both free parameters $\Gamma_{1}$ and $C_{1}$.

\subsection{Sensitivity study}

In order to estimate the uncertainties and the influence of the free parameters $\Gamma_{1}$ and $\mathrm{C}_{1}$ on the solution of the equation system (7) and (8) we performed a sensitivity study. For this analysis we use all $\mathrm{SF}_{6}$ and $\mathrm{CO}_{2}$ distributions in the $\varphi_{e}-\theta$ coordinate system derived from simultaneous measurements during SPURT. The difference

$\Delta \alpha_{1}\left(\Gamma_{1}, C_{1}\right)=\left|\alpha_{1, \mathrm{SF} 6}-\alpha_{1, \mathrm{CO} 2}\right|$ of the tropospheric fractions calculated from $\mathrm{SF}_{6}$ and $\mathrm{CO}_{2}$ which should reduce to zero under ideal conditions is a direct measure for the quality of the numerical results. In an analogue manner to the width calculation of the mode $\mathrm{G}_{2}$, we use the parameterisation given in Eqs. (5), whereas the constant $\mathrm{C}_{1}$ is not predefined for the mode $\mathrm{G}_{1}$.

As an example Fig. 5 shows a sensitivity analysis of the parameter $\Delta \alpha_{1}\left(\Gamma_{1}, C_{1}\right)$ for the campaign $\mathrm{S} 2$ in January. For clarity, the results are shown for the mean $\mathrm{CO}_{2}$ and $\mathrm{SF}_{6}$ values in each bin and not for all simultaneous measurements of both tracers. The quantity $\Delta \alpha_{1}$ has a strong minimum for $\mathrm{C}_{1}=0.05$ and 0.20 years which disappears for larger values of $C_{1}$, i.e. for broader age spectra. For this example, the maximum differences for $\Delta \alpha_{1}$ (and therefore also for $\Delta \alpha_{2}$ ) is about $20 \%$ and the average difference for $\Delta \alpha_{1}$ is about $5 \%$ given the parameterisation $C_{1}=0.2$ years and $\Gamma_{1}=0.3$ years.

Note also, that the ideal solution $\Delta \alpha_{1}=0$ for the equation system (6) can not be found for all simultaneously measured $\mathrm{SF}_{6}$ and $\mathrm{CO}_{2}$ mixing ratios. This is the consequence of the measurement errors and natural variability, but also of the idealised assumptions that have to be made for this mass balance, i.e. the parameterisation of the age spectrum, the control surface and the time series of $\mathrm{SF}_{6}$ and $\mathrm{CO}_{2}$ there.

However, our mass balance model is able to reproduce the mixing ratios of both tracers for the right choice of parameters. As shown in Fig. 5, simultaneously measured $\mathrm{SF}_{6}$ and $\mathrm{CO}_{2}$ mixing ratios in the LMS during the campaign $\mathrm{S} 2$ in January can be explained as a mixture of stratospheric air with a mean age of $\Gamma_{2}=3$ years and of tropospheric air originating from the tropics and subtropics. The deviations $\Delta \alpha_{1}$ are similar for the other SPURT campaigns for the specific best choice of parameters.

Another result of the sensitivity analysis (not shown here) is that for all campaigns the parameter $\Gamma_{1}$ is highly variable in the range of 0.05 to 0.8 years, if accounting for all SPURT $\mathrm{SF}_{6}$ and $\mathrm{CO}_{2}$ measurements. $\Gamma_{1}$ is characteristic for an air parcel and describes the mean transit time from the tropospheric source region to the point of measurement in the LMS. A detailed discussion of the variability of $\Gamma_{1}$ is given in the following section. In contrast to $\Gamma_{1}$, the parameter $C_{1}$ varies only slightly in the range of 0.05 to 0.25 years for numerical solution of equation system (7). Furthermore, the changes of $\Delta \alpha_{1}$ are not really significant for the variation of $C_{1}$ in these ranges and therefore we decided to fix the parameter $C_{1}$ to 0.1 years for all following calculations.

\subsection{Results}

As shown before, we derive from simultaneous measured $\mathrm{SF}_{6}$ and $\mathrm{CO}_{2}$ mixing ratios the tropospheric fraction $\alpha_{1}$ (and the stratospheric fraction $\alpha_{2}=1-\alpha_{1}$ ) of an air parcel located in the LMS by numerically solving the mass balance Eqs. (7) and (8). An iterative non-linear least squares algorithm is used to find the solution by varying the remaining free parameter $\Gamma_{1}$. This means that our method allows us to derive 

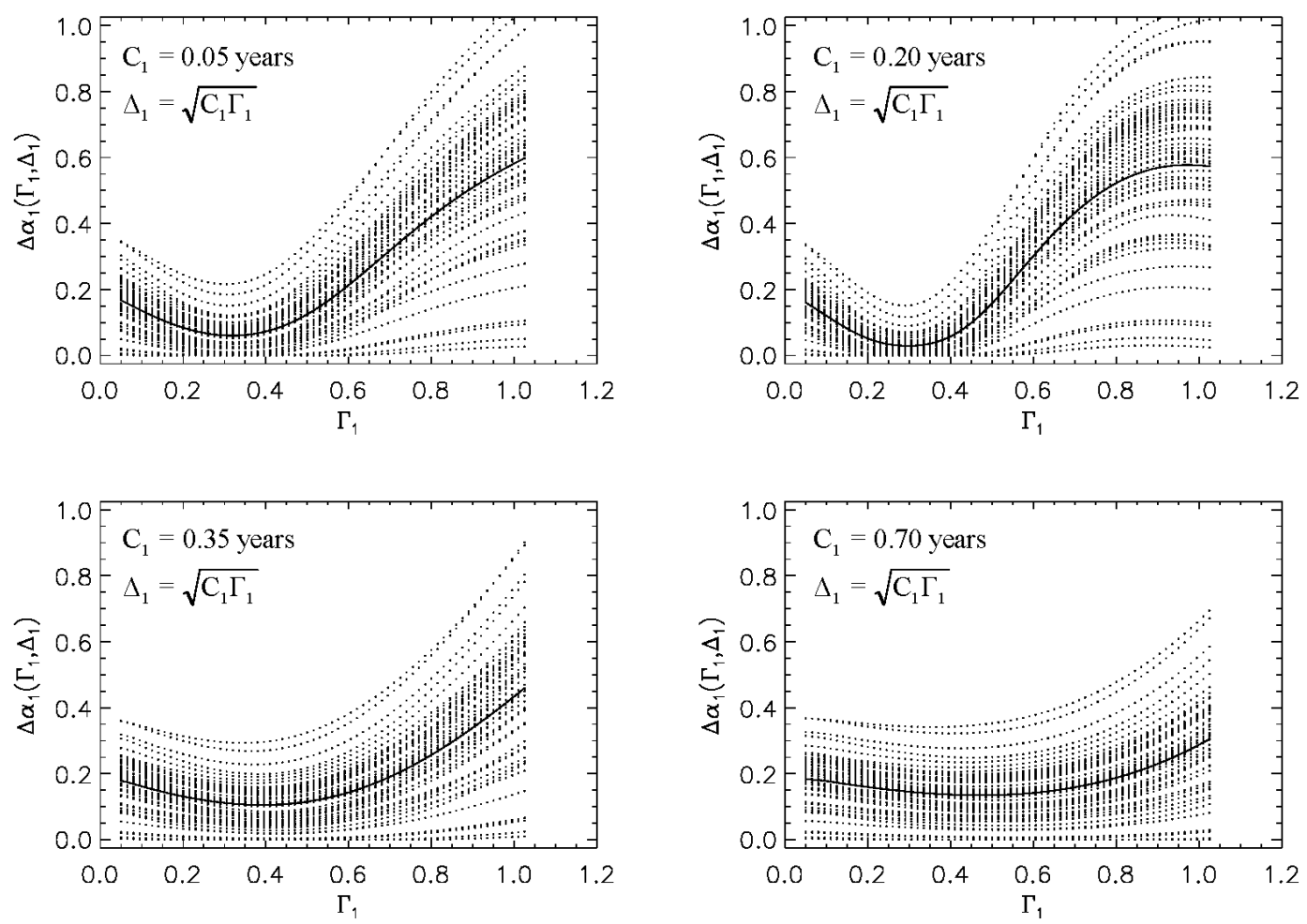

Fig. 5. Quality of fit parameter $\Delta \alpha_{1}=\alpha_{1, \mathrm{SF}_{6}}-\alpha_{1, \mathrm{CO} 2}$ as a function of $\Gamma_{1}$ and $\Delta_{1}$ calculated from the mean values of $\mathrm{SF}_{6}\left(\varphi_{e}, \theta\right)$ and $\mathrm{CO}_{2}\left(\varphi_{e}, \theta\right)$ distributions in each $5^{\circ}$ latitude and $5 \mathrm{~K}$ potential temperature bin observed during campaign $\mathrm{S} 2$ in January. The bold lines indicate the average of $\Delta \alpha_{1}$.

the corresponding mean transit time $\Gamma_{1}$ from the control surface to the specific location in the LMS for each tropospheric fraction $\alpha_{1}$. This additional information of the mean transit time represents a strong progress for quantification of transport into the LMS from tracer measurements.

Figure 6 shows the distribution of the tropospheric fraction $\alpha_{1}$ as a function of equivalent latitude $\varphi_{e}$ and potential temperature $\theta$ from SPURT $\mathrm{SF}_{6}$ and $\mathrm{CO}_{2}$ measurements. The applied fixed parameter set for the calculation is $\mathrm{C}_{1}=0.1$ years, $C_{2}=0.7$ years and $\Gamma_{2}=3$ years (see Sects. 4.1 and 4.2). In the region where $\Gamma_{\mathrm{SF} 6}<0.3$ years (see Sect. 3.2), which is below the lower boundary for our mass balance (see Sect. 4.1) the fraction $\alpha_{1}$ is simply set to $100 \%$, denoting purely tropospheric air. We could not calculate the tropospheric fractions for July because the required $\mathrm{CO}_{2}$ measurements were not available for this campaign due to technical problems.

Consistent with the findings derived from the mean age of air distributions (see Fig. 2), the highest stratospheric influence on the LMS is found in April (S7) and the strongest tropospheric influence in October (S5). Thus, the seasonal characteristics of the tropospheric fractions $\alpha_{1}$ mirror the findings from the mean age distribution indicating more tropospheric air during summer/autumn corresponding to younger air. It appears that tropospheric fractions $\alpha_{1}>80 \%$ can be found during all seasons in the LMS even in the region where the potential vorticity $(\mathrm{PV})$ is greater than $6 \mathrm{pvu}$. Note that PV, which is the product of relative vorticity and vertical stratification is adiabatically conserved (Ertel, 1942; Haynes and McIntyre, 1990; Lait, 1994). A level of $P V=2$ pvu is often used to define the dynamical extratropical tropopause (e.g. Holton et al., 1995). Air masses with tropospheric fractions $\alpha_{1}<60 \%$ have been observed only during winter and spring above the theta level of $345 \mathrm{~K}$. Especially in October, there are hardly any air masses with tropospheric fractions $\alpha_{1}<90 \%$ in the LMS.

Figure 7 displays the mean transit time $\Gamma_{1}$ from the troposphere or more precisely from the earth surface (not from the tropopause) into the LMS derived from our mass balance approach in the same way as the associated tropospheric fraction $\alpha_{1}$ in Fig. 6. Just as $\alpha_{1}$, the mean transit time $\Gamma_{1}$ can only be calculated in the domain 0.3 years $<\Gamma_{\mathrm{SF} 6}<3$ years where our mass balance is defined, but unlike $\alpha_{1}$, we do not make any assumption for $\Gamma_{1}$ below the area of validity. Obviously the tropospheric influence in the LMS, mapped by the parameter $\alpha_{1}$, is associated with different mean transit times $\Gamma_{1}$. On average, the longest mean transit times $\Gamma_{1}$ of about 0.6 years are observed in May (S3) and the shortest of about 0.2 years in August. The latter is consistent with the findings of Ray et al. (1999) who estimated transit times of roughly 1.5 month for September. 


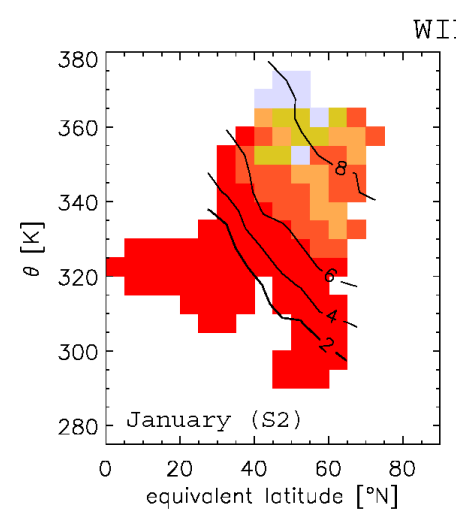

WINTER

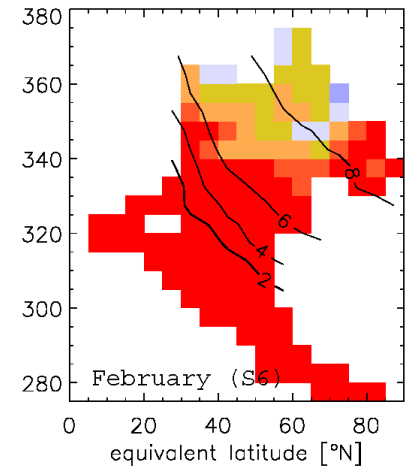

SUMMER
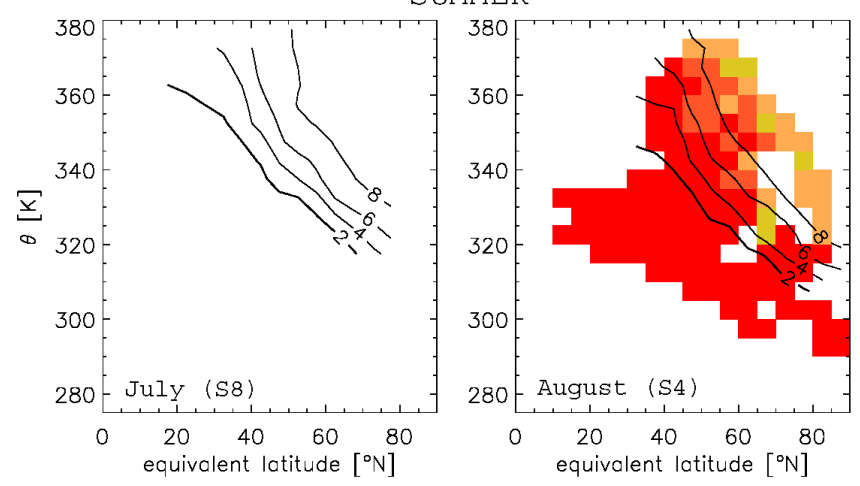
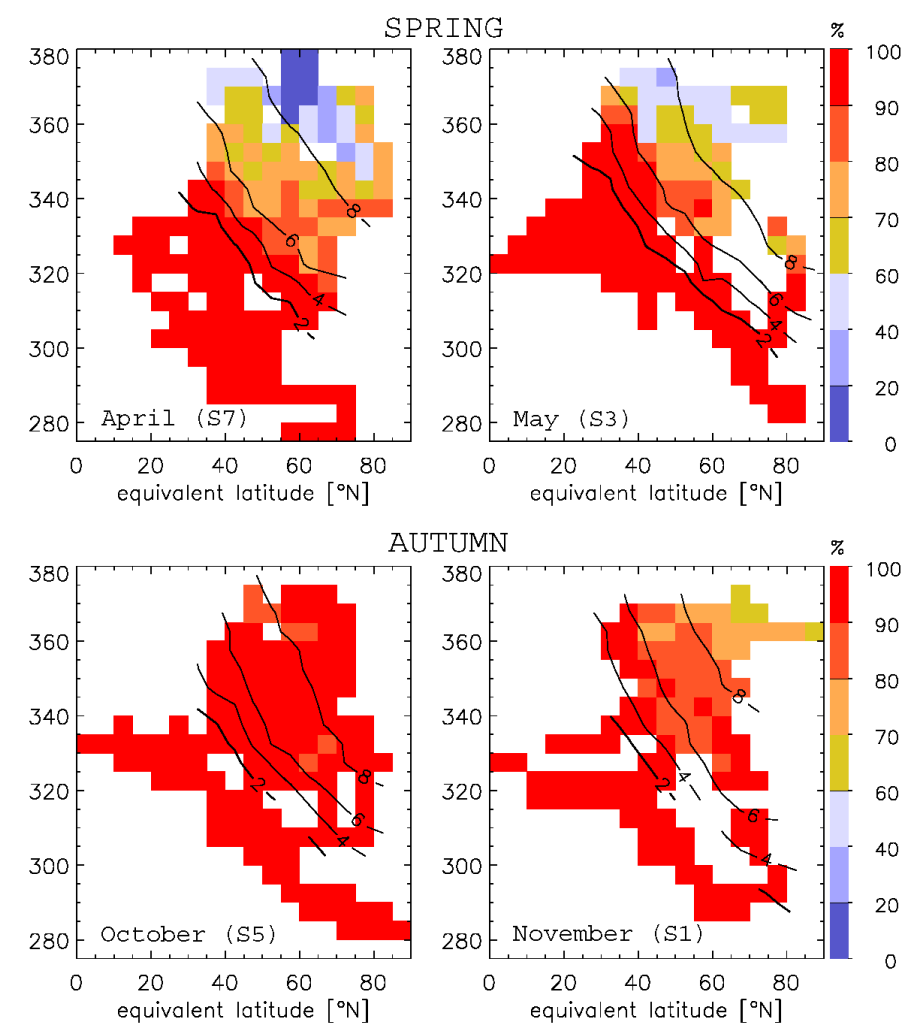

Fig. 6. Seasonal variation of the tropospheric fraction $\alpha_{1}$ as a function of $\varphi_{e}$ and $\theta$ calculated from all simultaneous measurements of $\mathrm{SF}_{6}$ and $\mathrm{CO}_{2}$ during SPURT. The lines indicate the PV-isolines.

In order to get an overall picture of the transport and mixing into the LMS, it is necessary to combine the information from the distribution of tropospheric fractions $\alpha_{1}\left(\varphi_{e}, \theta\right)$ (Fig. 6) and of the associated mean transit times $\Gamma_{1}\left(\varphi_{e}, \theta\right)$ (Fig. 7):

During winter, the influence of stratospheric air in the LMS with $\alpha_{2}>30 \%$ (or $\alpha_{1}<70 \%$, respectively) occurs only above $\theta=350 \mathrm{~K}$ in mid and high latitudes $\left(35^{\circ} \mathrm{N}<\varphi_{e}<75^{\circ} \mathrm{N}\right)$ even though the downward transport through the $380 \mathrm{~K}$ isentrope is at maximum in the extratropical stratosphere during this time (Appenzeller et al., 1996). The mean transit times $\Gamma_{1}$ for the fast transport branch are very homogeneously distributed throughout the whole LMS being about 0.1 years longer in February ( 0.4 years $<\Gamma_{1}<0.5$ years) than in January ( 0.3 years $<\Gamma_{1}<0.4$ years). This implies that the observed tropospheric fraction $\alpha_{1}$ in winter has entered the LMS predominantly during August and September. During winter the subtropical jet is strongest, inhibiting additional quasi-horizontal mixing which would add significant amounts of even younger air and de-homogenize also the distribution of the mean transit time $\alpha_{1}$. In combination with the strongest downward transport and weak quasi-horizontal STE in winter only those air masses, which entered the stratosphere above the subtropical jet possibly across the tropical tropopause in autumn are advected to the SPURT locations, where they were observed during winter.
During spring, the strongest impact of air originating from the overworld can be observed in the LMS above the level $\mathrm{PV}>6$ pvu. The mean transit times $\Gamma_{1}$ increase compared to winter and reach their intra-annual maximum in May (S3). The distribution of $\Gamma_{1}\left(\varphi_{e}, \theta\right)$ is much more inhomogeneous in April (S7), when the tropospheric influence is minimal, than in May. Our study suggests that the major part of tropospheric air observed during both spring campaigns was caused by tracer transport into the LMS during September to November of the previous year. For the campaign in April some influence from TST in early winter is detectable, which is responsible for the observed enhanced variability of $\Gamma_{1}\left(\varphi_{e}, \theta\right)$ distribution.

During summer, the LMS is dominated by tropospheric air. The calculated values for the tropospheric fraction $\alpha_{1}$ are exclusively in the range of $70 \%$ to $100 \%$. This strong tropospheric influence is directly linked to the shortest mean transit times $\Gamma_{1}$ into the LMS in the course of the year. Even above the level of PV $>8$ pvu, transit times $\Gamma_{1}$ of less than 0.2 years are derived. On average these are the shortest transit times we have derived from the entire data set. This agrees well with the high tropospheric fraction $\alpha_{1}$ and indicates that quasi-horizontal mixing is at maximum in summer when the mixing barrier for isentropic tracer transport into the LMS the subtropical jet - is weakest (e.g. Hegglin and Shepherd, 2006). 


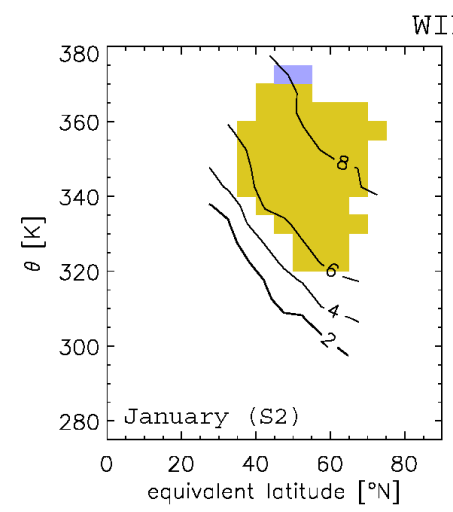

WINTER
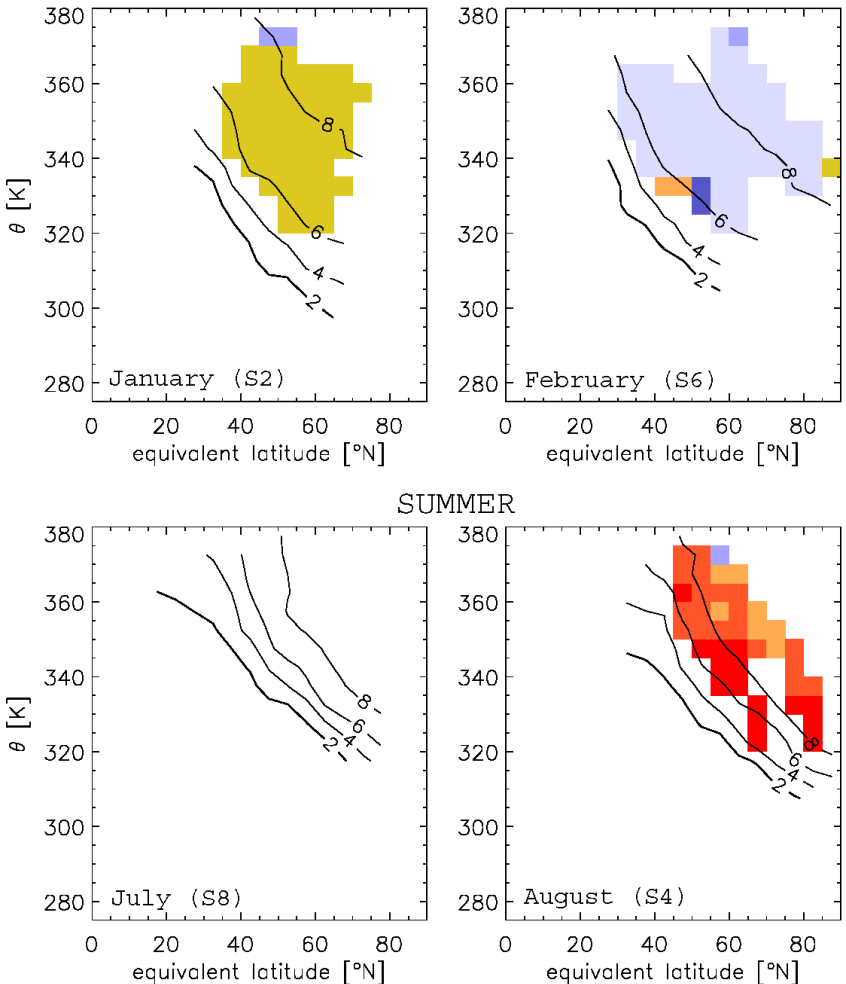

SUMMER

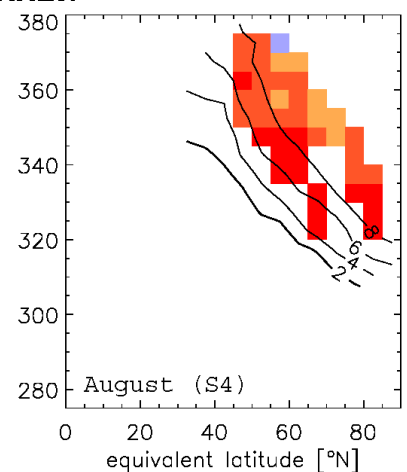

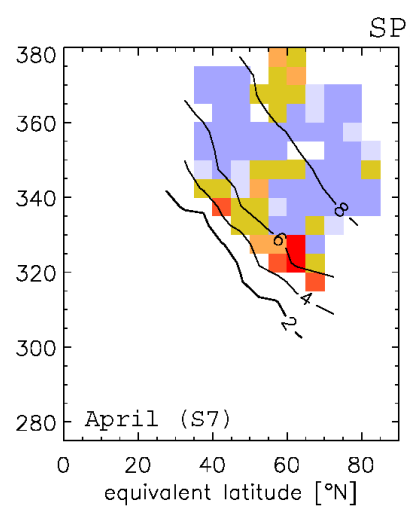

SPRING
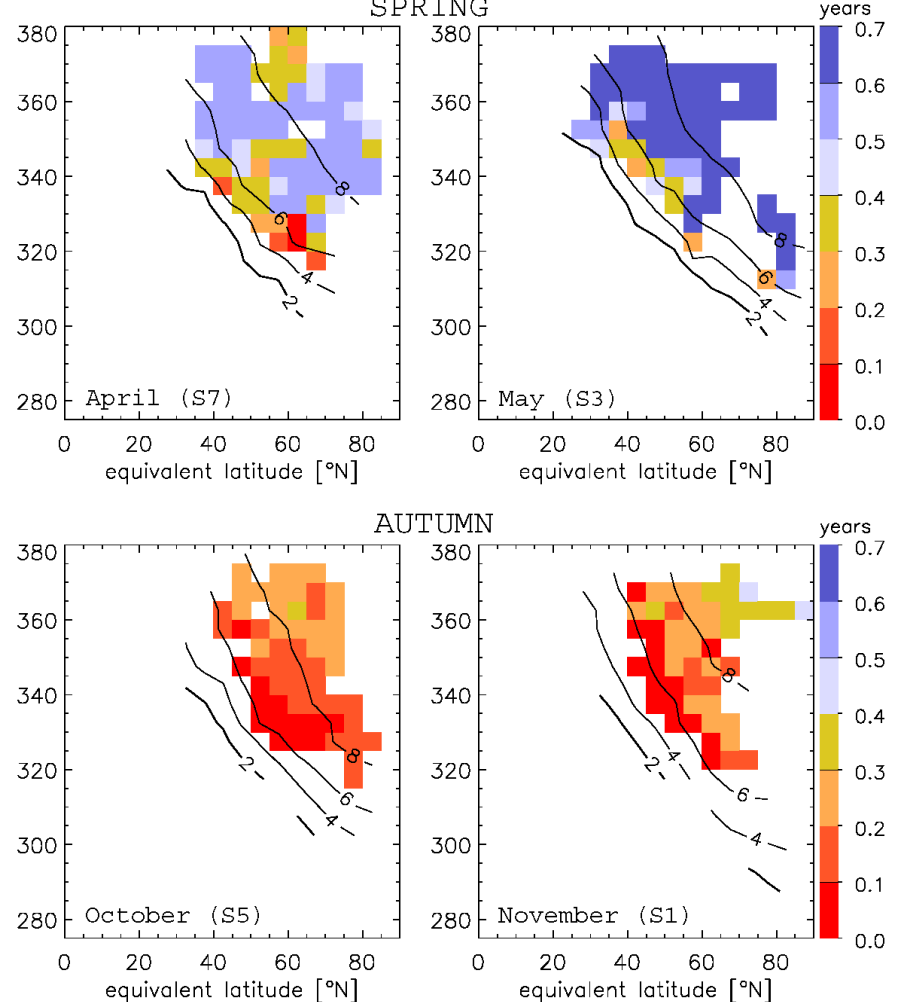

AUTUMN

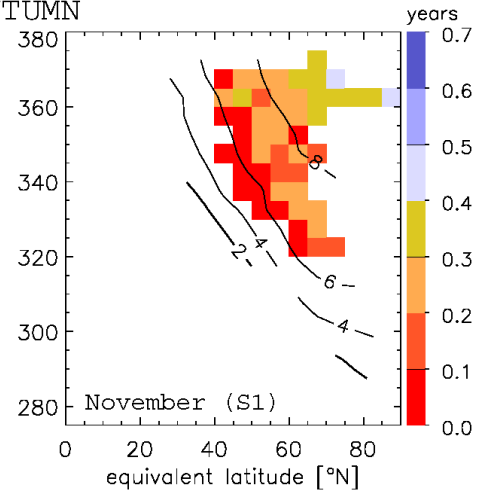

Fig. 7. Seasonal variation of the mean transit time $\Gamma_{1}$ associated to the tropospheric fraction $\alpha_{1}$ as a function of $\varphi_{e}$ and $\theta$ calculated from all simultaneous measurements of $\mathrm{SF}_{6}$ and $\mathrm{CO}_{2}$ during SPURT. The lines indicate the PV-isolines.

During autumn, the LMS is, similar to August, characterised by a strong influence of tropospheric air. The mean age calculations showed that the youngest air is found in October (Fig. 2) and consequently, the intra-annual maximum values for the tropospheric fraction are found during October with $\alpha_{1}>80 \%$ throughout the LMS. In November, when downward transport, driven by planetary Rossby wave drag, in the Northern Hemisphere extratropical stratosphere starts to increase, the tropospheric fraction $\alpha_{1}$ begins to decrease slightly below $80 \%$. This decrease occurs first in the upper LMS layers $(\theta>355 \mathrm{~K})$ at higher equivalent latitudes $\left(60^{\circ} \mathrm{N}<\varphi_{e}<90^{\circ} \mathrm{N}\right)$. The associated mean transit times $\Gamma_{1}$ are $<0.3$ years in October and $<0.5$ years in November throughout the LMS. Note, that the longer transit times of $\Gamma_{1}>0.3$ years in November are only observed in the region where stratospheric influence is getting stronger $\left(\alpha_{2}>20 \%\right)$. These short transit times calculated for both campaigns performed in autumn indicate that the entry of tropospheric air along the fast transport pathways described by the mode $\mathrm{G}_{1}$ of the underlying age spectra has occurred exclusively in summer.

\section{Conclusion and outlook}

This work is focused on the LMS above the so called ExTL or TIL which is characterised by a strong coupling to the troposphere with short transport time scales on the order of a few days (Hoor et al., 2004). In our region of interest, where mixing across the local tropopause only plays a minor role - we would like to call it the "free lowermost stratosphere" - the characteristics of transport changes drastically compared to the ExTL, which is governed by short-term local processes. In contrast, the transport time scales in the free LMS are on the order of weeks up to several months. This part of the LMS is dominated by quasihorizontal mixing across the subtropical tropopause in summer/autumn and transport from the tropical controlled transition layer $(380 \mathrm{~K}<\theta<450 \mathrm{~K})$ (Rosenlof et al., 1997). In higher latitudes both interact with downward transport from the overworld driven by the Brewer-Dobson circulation. The relatively homogeneous distribution of $\mathrm{G}_{1}$ indicates that the impact of troposphere-to-stratosphere tracer transport across the extratropical tropopause seems to play a minor role in the free LMS and is restricted to processes at the local tropopause in the ExTL. These findings are consistent with those of Hoor et al. (2004), based on the propagation of the tropospheric $\mathrm{CO}_{2}$ seasonal cycle into the LMS and the 
vertical distribution of $\mathrm{CO}$ relative to the local tropopause. In this study, we have derived a method which allows quantifying the time scales and the mass fractions of different transport pathways into the LMS.

Our analysis shows that TST into the northern hemispheric LMS accounting for the chemical composition above the ExTL has a pronounced seasonality. The tropospheric fraction $\alpha_{1}$ has its minimum in April when extreme values of $\alpha_{1}$ below $20 \%$ can be found in the highest levels of the LMS. In October, the tropospheric fraction maximises with values of $\alpha_{1}>90 \%$ throughout the LMS. This is consistent with the findings derived from mean age of air distributions $\Gamma_{\mathrm{SF} 6}\left(\varphi_{e}, \theta\right)$ calculated from $\mathrm{SF}_{6}$ measurements, which show the oldest air in April and the youngest in October. During all seasons, tropospheric fractions $\alpha_{1}>60 \%$ can occasionally be found in the LMS even above the level of PV $>8$ pvu. Combined with the dryness of the LMS in autumn these results suggest that quasi-horizontal transport from the TTL across the subtropical jet and from just above the tropical tropopause with subsequent subsidence are the dominating transport pathways into the free LMS.

A short pathway exists, connecting the tropical tropopause with the free LMS within the stratospheric residual circulation (e.g. Shepherd, 2007). This pathway corresponds to the lower branch of the Brewer-Dobson circulation which is mainly driven by transient synoptic scale eddies (as opposed to the deep branch driven by planetary waves). During summer the Brewer-Dobson circulation is almost exclusively composed out of the lower branch with close to zero circulation above about $20 \mathrm{~km}$ altitude (which is the approximate location of the zero wind line). We suggest that the residual transport time-scales within the lower branch of the Brewer-Dobson circulation associated with the so-called tropical controlled transition region (Rosenlof et al., 1997) are considerably shorter in summer than in winter. Such a "short-cut" has also been suggested by Hegglin et al. (2006) deduced from the seasonality of $\mathrm{N}_{2} \mathrm{O} / \mathrm{O}_{3}$ correlations measured during SPURT. In combination with the extreme weakening of the deep branch of the circulation this would also contribute to the picture of the free LMS as composed of much younger tropospheric air in summer and autumn compared to winter and spring.

The tropospheric fraction results are consistent with Hoor et al. (2005) who found a similar seasonality in the LMS above the ExTL. However, their tropospheric fractions are systematically lower since they use a CO based mass balance. This approach is sensitive for transport processes within the photochemical lifetime of $\mathrm{CO}$ which is on the order of 3 months. In contrast to the $\mathrm{SF}_{6} / \mathrm{CO}_{2}$ based method applied here, transport and mixing processes exceeding the photochemical lifetime of $\mathrm{CO}$ contribute to the stratospheric fraction in the study of Hoor et al. (2005). Thus, the CO based tropospheric fractions have to be regarded as net mass fractions of air, which have been transported from the troposphere into the LMS within the lifetime of CO.
The associated mean transit times $\Gamma_{1}$ which we report for the first time in a mass balance study derived from in-situ tracer measurements have a different seasonality than the tropospheric fractions $\alpha_{1}$. On average, the mean transit times have a minimum of $\Gamma_{1}<0.3$ years during August and a maximum of $\Gamma_{1}>0.5$ years during May in the free LMS, whereby $\Gamma_{1}$ increases continuously from August to May. This seasonality indicates that strong quasi-horizontal mixing across the weak subtropical jet and the dominance of the lower branch localised in the "tropical controlled transition region" over the deeper branch of the Brewer-Dobson circulation from above $20 \mathrm{~km}$ during summer to mid of autumn dominates the tropospheric influence and therefore also the chemical composition of the free LMS up to May. Even though downward transport across the $380 \mathrm{~K}$ isentrope is decreasing from January to May the stratospheric influence in the LMS is getting stronger due to weaker quasi-horizontal mixing across the strong subtropical jet during winter. In summary, we conclude that the LMS is flushed with tropospheric air during summer and that this in-mixing can be traced back till the end of spring the following year.

Our mass balance approach is also a valuable tool for evaluating model transport in the extratropical UTLS. It can be applied to modelled $\mathrm{SF}_{6}$ and $\mathrm{CO}_{2}$ fields to diagnose if the time scales for tracer transport into the LMS have been simulated correctly (e.g. Boenisch et al., 2008). If both tracers have been implemented in a full chemistry model run, the mass balance approach can also serve to distinguish whether chemical and/or transport and mixing processes may cause observed discrepancies to measurements of non-passive tracers. Also, it might be worth to compare our results directly with age spectra derived from so called "pulse experiments" used in mean age of air studies or with age spectra derived from a Lagrangian scheme.

The high resolution $\mathrm{SF}_{6}$ and $\mathrm{CO}_{2}$ measurements obtained during the SPURT campaigns allow for a comprehensive view of the LMS region above Europe. Despite the large seasonal and spatial data coverage, SPURT alone can obviously not provide a climatology and the results presented here only apply for the region and time of the SPURT observations and have to be confirmed by further investigations and measurements.

Acknowledgements. This work is partly funded by the project SPURT under the AFO 2000 program of the German Ministry for Education and Research (BMBF).

The authors acknowledge the Halocarbons and other Atmospheric Trace Species Group (HATS) from NOAA/ESRL Global Monitoring Division for the $\mathrm{SF}_{6}$ data set and the Globalview- $\mathrm{CO}_{2}$ project for the $\mathrm{CO}_{2}$ tropospheric reference data.

Furthermore, we acknowledge in particular Christian Gurk and Horst Fischer from MPI for Chemistry Mainz for the SPURT $\mathrm{CO}_{2}$ data, Marc Krebsbach from University Wuppertal, Cornelius Schiller and Nicole Spelten from Research Centre Jülich for the SPURT $\mathrm{H}_{2} \mathrm{O}$ data and Heini Wernli from University Mainz and 
Dominik Brunner from EMPA Switzerland for meteorological support of the SPURT campaigns.

Finally we would like to thank the enviscope GmbH (Frankfurt a. M., Germany) and the Gesellschaft für Flugzieldarstellung (GFD) for excellent co-operation and support during the aircraft campaigns.

Edited by: P. Haynes

\section{References}

Andrews, D. G., Holton, J. R., and Leovy, C. B.: Middle Atmosphere Dynamics, Academic Press, 1987.

Andrews, A. E., Boering, K. A., Daube, B. C., Wofsy, S. C., Hintsa, E. J., Weinstock, E. M., and Bui, T. P.: Empirical age spectra for the lower tropical stratosphere from in situ observations of $\mathrm{CO}_{2}$ : Implications for stratospheric transport, J. Geophys. Res., 104, 26581-26595, 1999.

Andrews, A. E., Boering, K. A., Wofsy, S. C., Daube, B. C., Jones, D. B., Alex, S., Loewenstein, M., Podolske, J. R., and Strahan, S. E.: Empirical age spectra for the midlatitude lower stratosphere from in situ observations of $\mathrm{CO}_{2}$ : Quantitative evidence for a subtropical "barrier" to horizontal transport, J. Geophys. Res., 106(D10), 10257-10274, 2001.

Appenzeller, C., Holton, J. R., and Rosenlof, K. H.: Seasonal variation of mass transport across the tropopause, J. Geophys. Res., 101(D10), 15071-15078, doi:10.1029/96JD00821, 1996.

Berthet, G., Esler, J. G., and Haynes, P. H.: A Lagrangian perspective of the tropopause and the ventilation of the lowermost stratosphere, J. Geophys. Res., 112, D18102, doi:10.1029/2006JD008295, 2007.

Birner, T.: Fine-scale structure of the extratropical tropopause region, J. Geophys. Res., 111, D04104, doi:10.1029/2005JD006301, 2006.

Boering, K. A., Daube, B. C., Wofsy, S. C., Loewenstein, M., Podolske, J. R., and Keim, E. R.: Tracer-tracer relationships and lower stratospheric dynamics: $\mathrm{CO}_{2}$ and $\mathrm{N}_{2} \mathrm{O}$ correlations during SPADE, Geophys. Res. Lett., 21(23), 2567-2570, 1994.

Boering, K. A., Wofsy, S. C., Daube, B. C., Schneider, H. R., Loewenstein, M., and Podolske, J. R.: Stratospheric mean ages and transport rates from observations of carbon-dioxide and nitrous-oxide, Science, 274, 1340-1343, 1996.

Bönisch, H., Hoor, P., Gurk, Ch., Feng, W., Chipperfield, M., Engel, A., and Bregman, B.: Model evaluation of $\mathrm{CO}_{2}$ and $\mathrm{SF}_{6}$ in the extratropical UT/LS region, J. Geophys. Res., 113, D06101, doi:10.1029/2007JD008829, 2008.

Brioude, J., Cammas, J.-P., Cooper, O. R., and Nedelec, P.: Characterization of the composition, structure, and seasonal variation of the mixing layer above the extratropical tropopause as revealed by MOZAIC measurements, J. Geophys. Res., 113, D00B01, doi:10.1029/2007JD009184, 2008.

Chen, P.: Isentropic cross-tropopause mass exchange in the extratropics, J. Geophys. Res., 100, 16661-16674, 1995.

Chhikara, R. S. and Folks, J. L.: The Inverse Gaussian Distribution: Theory, Methodology and Applications, Marcel Dekker, New York, 1989.

Curtius, J., Weigel, R., Vssing, H.-J., Wernli, H., Werner, A., Volk, C.-M., Konopka, P., Krebsbach, M., Schiller, C., Roiger, A.,
Schlager, H., Dreiling, V., and Borrmann, S.: Observations of meteoric material and implications for aerosol nucleation in the winter Arctic lower stratosphere derived from in situ particle measurements, Atmos. Chem. Phys., 5, 3053-3069, 2005, http://www.atmos-chem-phys.net/5/3053/2005/.

Dessler, A. E., Hintsa, E. J., Weinstock, E. M., Anderson, J. G., and Chan, K. R.: Mechanisms controlling water vapor in the lower stratosphere: "A tale of two stratospheres", J. Geophys. Res., 100, 23167-23172, 1995.

Dvortsov, V. L., Geller, M. A., Solomon, S., Schauffler, S. M., Atlas, E. L., and Blake, D. R.: Rethinking reactive halogen budgets in the midlatitude lower stratosphere, Geophys. Res. Lett., 26, 1699-1702, 1999.

Elkins, J. W., Fahey, D. W., Gilligan, J. M., Dutton, G. S., Baring, T. J., Volk, C. M., Dunn, R. E., Myers, R. C., Montzka, S. A., Wamsley, P. R., Hayden, A. H., Butler, J. H., Thompson, T. M., Swanson, T. H., Dlugokencky, E. J., Novelli, P. C., Hurst, D. F., Lobert, J. M., Ciciora, S. J., McLaughlin, R. J., Thompson, T. L., Winkler, R. H., Fraser, P. J., Steele, L. P., and Lucarelli, M. P.: Airborne gas chromatograph for in situ measurements of long lived species in the upper troposphere and lower stratosphere, Geophys. Res. Lett., 23, 347-350, 1996.

Engel, A., Strunk, M., Müller, M., Haase, H.-P., Poss, C., Levin, I., and Schmidt, U.: The temporal development of total chlorine in the high latitude stratosphere based on reference distributions of mean age derived from $\mathrm{CO}_{2}$ and $\mathrm{SF}_{6}$, J. Geophys. Res., 107, 4136, doi:10.1029/2001JD000584, 2002.

Engel, A., Bönisch, H., Brunner, D., Fischer, H., Franke, H., Günther, G., Gurk, C., Hegglin, M., Hoor, P., Königstedt, R., Krebsbach, M., Maser, R., Parchatka, U., Peter, T., Schell, D., Schiller, C., Schmidt, U., Spelten, N., Szabo, T., Weers, U., Wernli, H., Wetter, T., and Wirth, V.: Highly resolved observations of trace gases in the lowermost stratosphere and upper troposphere from the Spurt project: an overview, Atmos. Chem. Phys., 6, 283-301, 2006a, http://www.atmos-chem-phys.net/6/283/2006/.

Engel, A., Möbius, T., Haase, H.-P., Bönisch, H., Wetter, T., Schmidt, U., Levin, I., Reddmann, T., Oelhaf, H., Wetzel, G., Grunow, K., Huret, N., and Pirre, M.: Observation of mesospheric air inside the arctic stratospheric polar vortex in early 2003, Atmos. Chem. Phys., 6, 267-282, 2006b,

http://www.atmos-chem-phys.net/6/267/2006/.

Ertel, H.: Ein neuer hydrodynamischer Wirbelsatz. Meteor. Z., 59, 277-281, 1942.

Fischer, H., Wienhold, F. G., Hoor, P., Bujok, O., Schiller, C., Siegmund, P., Ambaum, M., Scheeren, H. A., and Lelieveld, J.: Tracer correlations in the northern high latitude lowermost stratosphere: Influence of cross-tropopause mass exchange, Geophys. Res. Lett., 27(1), 97-100, 2000.

Forster, P. M. D. and Shine, K. P.: Radiative forcing and temperature trends from stratospheric ozone changes, J. Geophys. Res., 102(D9), 10841-10855, 1997.

Fueglistaler, S., Wernli, H., and Peter, T.: Tropical tropospheretostratosphere transport inferred from trajectory calculations, J. Geophys. Res., 109, D03108, doi:10.1029/2003JD004069, 2004.

Fueglistaler, S., Bonazzola, M., Haynes, P. H., and Peter, T.: Stratospheric water vapor predicted from the Lagrangian temperature history of air entering the stratosphere in the tropics, J. Geophys. Res., 110, D08107, doi:10.1029/2004JD005516, 2005. 
GLOBALVIEW-CO2: Cooperative Atmospheric Data Integration Project-Carbon Dioxide., CD-ROM, NOAA-ESRL, Boulder, Colorado, also available on Internet via anonymous FTP to ftp.cmdl.noaa.gov, Path: ccg/co2/GLOBALVIEW, 2007.

Gurk, Ch., Fischer, H., Hoor, P., Lawrence, M. G., Lelieveld, J., and Wernli, H.: Airborne in-situ measurements of vertical, seasonal and latitudinal distributions of carbon dioxide over Europe, Atmos. Chem. Phys., 8, 6395-6403, 2008, http://www.atmos-chem-phys.net/8/6395/2008/.

Hall, T. M. and Plumb, R. A.: Age as a diagnostic of stratospheric transport, J. Geophys. Res., 99, 1059-1070, 1994.

Hall, T. M. and Waugh, D. W.: Influence of nonlocal chemistry on tracer distributions: inferring mean age of air from $\mathrm{SF}_{6}, \mathrm{~J}$. Geophys. Res., 103(D11), 13327-13336, 1998.

Haynes, P. H. and McIntyre, M. E.: On the conservation and impermeability theorems for potential vorticity, J. Atmos. Sci., 47, 2021-2031, 1990.

Haynes, P. H., Marks, C. J., McIntyre, M. E., Shepherd, T. G., and Shine, K. P.: On the "downward control" of extratropical diabatic circulations by eddy-induced mean zonal forces, J. Atmos. Sci., 48, 651-678, 1991.

Haynes, P. H. and Shuckburgh, E. F.: Effective diffusivity as a diagnostic of atmospheric transport: 2 . Troposphere and lower stratosphere, J. Geophys. Res., 105, 22795-22810, 2000.

Hegglin, M. I., Brunner, D., Wernli, H., Schwierz, C., Martius, O., Hoor, P., Fischer, H., Parchatka, U., Spelten, N., Schiller, C., Krebsbach, M., Weers, U., Staehelin, J., and Peter, Th.: Tracing troposphere-to-stratosphere transport above a mid-latitude deep convective system, Atmos. Chem. Phys., 4, 741-756, 2004, http://www.atmos-chem-phys.net/4/741/2004/.

Hegglin, M. I., Brunner, D., Peter, T., Hoor, P., Fischer, H., Staehelin, J., Krebsbach, M., Schiller, C., Parchatka, U., and Weers, U.: Measurements of $\mathrm{NO}, \mathrm{NO}_{\mathrm{y}}, \mathrm{N}_{2} \mathrm{O}$, and $\mathrm{O}_{3}$ during SPURT: implications for transport and chemistry in the lowermost stratosphere, Atmos. Chem. Phys., 6, 1331-1350, 2006,

http://www.atmos-chem-phys.net/6/1331/2006/.

Hegglin, M. I. and Shepherd, T. G.: $\mathrm{O}_{3}-\mathrm{N}_{2} \mathrm{O}$ correlations from the Atmospheric Chemistry Experiment: Revisiting a diagnostic of transport and chemistry in the stratosphere, J. Geophys. Res., 112, D19301, doi:10.1029/2006JD008281, 2007.

Hegglin, M. I., Boone, C. D., Manney, G. L., and Walker, K. A.: A global view of the extratropical tropopause transition layer from Atmospheric Chemistry Experiment Fourier Transform Spectrometer $\mathrm{O}_{3}, \mathrm{H}_{2} \mathrm{O}$, and CO, J. Geophys. Res., 114, D00B11, doi:10.1029/2008JD009984, 2009.

Hintsa, E. J., Boerling, K. A., Weinstock, E. M., Anderson, J. G., Gary, B. L., Pfister, L., Daube, B. C., Wofsy, S. C., Loewenstein, M., Podolske, J. R., Margitan, J. J., and Bui, T. P.: Troposphere-to-stratosphere transport in the lowermost stratosphere from measurements of $\mathrm{H}_{2} \mathrm{O}, \mathrm{CO}_{2}, \mathrm{~N}_{2} \mathrm{O}$, and $\mathrm{O}_{3}$, Geophys. Res. Lett., 25, 2655-2658, 1998.

Holton, J. R., Haynes, P. H., McIntyre, M. E., Douglass, A. R., Rood, R. B., and Pfister, L.: Stratosphere-troposphere exchange, Rev. Geophys., 33, 403-439, 1995.

Hoor, P., Fischer, H., Lange, L., Lelieveld, J., and Brunner, D.: Seasonal variations of a mixing layer in the lowermost stratosphere as identified by the $\mathrm{CO}-\mathrm{O}_{3}$ correlation from in situ measurements, J. Geophys. Res., 107(D5), 4044, doi:10.1029/2000JD000289, 2002.
Hoor, P., Gurk, C., Brunner, D., Hegglin, M. I., Wernli, H., and Fischer, H.: Seasonality and extent of extratropical TST derived from in-situ CO measurements during SPURT, Atmos. Chem. Phys., 4, 1427-1442, 2004, http://www.atmos-chem-phys.net/4/1427/2004/.

Hoor, P., Fischer, H., and Lelieveld, J.: Tropical and extratropical tropospheric air in the lowermost stratosphere over Europe: A CO-based budget, Geophys. Res., Lett., 32, L07802, doi:10.1029/2004GL022018, 2005.

James, P., Stohl, A., Forster, C., Eckhardt, S., Seibert, P., and Frank, A.: A 15-year climatology of stratosphere-troposphere exchange with a Lagrangian particle dispersion model: 1. Methodology and validation, J. Geophys. Res., 108(D12), 8519, doi:10.1029/2002JD002637, 2003a.

James, P., Stohl, A., Forster, C., Eckhardt, S., Seibert, P., and Frank, A.: A 15-year climatology of stratosphere-troposphere exchange with a Lagrangian particle dispersion model: 2. Mean climate and seasonal variability, J. Geophys. Res., 108, 8522, doi:10.1029/2002JD002639, 2003b.

Kida, H.: General circulation of air parcels and transport characteristics derived from a hemispheric GCM, Part 2, Very long-term motions of air parcels in the troposphere and stratosphere, J. Meteorol. Soc. Jpn., 61, 510-522, 1983.

Ko, M. K. W., Sze, N. D., Wang, W. C., Shia, G., Goldman, A., Murcray, F. J., Murcray, D. G., and Rinsland, C. P.: Atmospheric Sulfur-Hexafluoride - Sources, Sinks and Greenhouse Warming, J. Geophys. Res., 98, 10499-10507, 1993.

Ko, M. K. W., Poulet, G., Blake, D. R., et al.: Very short-lived halogen and sulfur substances, Chapter 2, in: Scientific Assessment of Ozone Depletion: 2002, Global Ozone Research and Monitoring Project - Report No. 47, World Meteorological Organization, Geneva, 2003.

Krebsbach, M., Schiller, C., Brunner, D., Gnther, G., Hegglin, M. I., Mottaghy, D., Riese, M., Spelten, N., and Wernli, H.: Seasonal cycles and variability of $\mathrm{O}_{3}$ and $\mathrm{H}_{2} \mathrm{O}$ in the UT/LMS during SPURT, Atmos. Chem. Phys., 6, 109-125, 2006, http://www.atmos-chem-phys.net/6/109/2006/.

Lacis, A. A., Wuebbles, D. J., and Logan, J. A.: Radiative forcing of climate by changes in the vertical distribution of ozone, J. Geophys. Res., 95, 9971-9981, 1990.

Lait, L. R.: An alternative form for potential vorticity, J. Atmos. Sci., 51, 1754-1759, 1994.

Laube, J. C., Engel, A., Bönisch, H., Möbius, T., Worton, D. R., Sturges, W. T., Grunow, K., and Schmidt, U.: Contribution of very short-lived organic substances to stratospheric chlorine and bromine in the tropics a case study, Atmos. Chem. Phys., 8, 7325-7334, 2008, http://www.atmos-chem-phys.net/8/7325/2008/.

Law, K. S., Sturges, W. T., Blake, D. R., et al.: Halogenated very short-lived substances, Scientific assessment of ozone depletion: 2006, Global Ozone Research and Monitoring Project, World Meteorological Organization, Geneva, Switzerland, Report No. 50, Chapter 2, 2007.

Levine, J. G., Braesicke, P., Harris, N. R. P., Savage, N. H., and Pyle, J. A.: Pathways and timescales for troposphere-tostratosphere transport via the tropical tropopause layer and their relevance for very short lived substances, J. Geophys. Res., 112, D04308 doi:10.1029/2005JD006940, 2007.

Maiss, M. and Levin, I.: Global increase of $\mathrm{SF}_{6}$ observed in the 
atmosphere, Geophys. Res. Lett., 21(7), 569-572, 1994.

NOAA-ESRL, Halocarbons \& other Atmospheric Trace Species Group (HATS), available on Internet via anonymous FTP to ftp.cmdl.noaa.gov, Path: hats/sf6/flasks, 2007.

Olsen, M. A., Douglass, A. R., Newman, P. A., Gille, J. C., Nardi, B., Yudin, V. A., Kinnison, D. E., and Khosravi, R.: HIRDLS observations and simulation of a lower stratospheric intrusion of tropical air to high latitudes, Geophys. Res. Lett., 35, L21813, doi:10.1029/2008GL035514, 2008.

Pan, L. L., Hintsa, E. J., Stone, E. M., Weinstock, E. M., and Randel, W. J.: The seasonal cycle of water vapour and saturation vapor mixing ratio in the extratropical lowermost stratosphere, J. Geophys. Res., 105(D21), 26519-26530, doi:10.1029/2000JD900401, 2000.

Pan, L. L., Randel W. J., Gary, B. L., Mahoney, M. J., and Hintsa, E. J.: Definitions and sharpness of the extratropical tropopause: A trace gas perspective, J. Geophys. Res., 109, D23103, doi:10.1029/2004JD004982, 2004.

Randel, W. J., Wu, F., and Forster, P.: The Extratropical Tropopause Inversion Layer: Global Observations with GPS Data, and a Radiative Forcing Mechanism. J. Atmos. Sci., 64, 4489-4496, 2007.

Ravishankara, A. R., Solomon, S., Turniseed, A. A., and Warren, R. F.: Atmospheric lifetimes of long-lived halogenated species, Science, 259, 194-199, 1993.

Ray, E. A., Moore, F. L., Elkins, J. W., Dutton, G. S., Fahey, D. W., Vömel, H., Oltmans, S. J., and Rosenlof, K. H.: Transport into the Northern Hemisphere lowermost stratosphere revealed by in situ tracer measurements, J. Geophys. Res., 104(D21), 2656526580, doi:10.1029/1999JD900323, 1999.

Ray, E. A., Moore, F. L., Elkins, J. W., Hurst, D. F., Romashkin, P. A., Dutton, G. S., and Fahey, D. W.: Descent and mixing in the 1999-2000 northern polar vortex inferred from in situ tracer measurements, J. Geophys. Res., 107, 8285, doi:10.1029/2001JD000961, 2002.

Reddmann, T., Ruhnke, R., and Kouker, W.: Three-dimensional model simulations of $\mathrm{SF}_{6}$ with mesospheric chemistry, J. Geophys. Res., 106, 14525-14537, 2001.
Rosenlof, K. H., Tuck, A. F., Kelly, K. K. Russel, J. M., and McCormick, M. P.: Hemispheric asymmetries in water vapor and inferences about transport in the lower stratosphere, J. Geophys. Res., 102(D11), 13213-13234, doi:10.1029/97JD00873, 1997.

Sawa, Y., Machida, T., and Matsueda, H.: Seasonal variations of $\mathrm{CO}_{2}$ near the tropopause observed by commercial aircraft, J. Geophys. Res., 113, D23301, doi:10.1029/2008JD010568, 2008.

Seshadri, V.: The Inverse Gaussian Distribution, Springer-Verlag, New York, 1999.

Schmidt, U. and Khedim, A.: In situ measurements of carbon dioxide in the winter arctic vortex and at midlatitudes: An indicator of the age of stratospheric air, Geophys. Res. Lett., 18, 763-766, 1991.

Shepherd, T. G.: Transport in the Middle Atmosphere, J. Meteorol. Soc. Jpn., 85B, 165-191, 2007.

Sprenger, M. and Wernli, H.: A northern hemispheric climatology of cross-tropopause exchange for the ERA15 time period (1979-1993), J. Geophys. Res., 108(D12), 8521, doi:10.1029/2002JD002636, 2003.

Strahan, S. E., Douglass, A. R., Nielsen, J. E., and Boering, K. A.: The $\mathrm{CO}_{2}$ seasonal cycle as a tracer of transport, J. Geophys. Res., 103, 13729-13741, 1998.

Strunk, M., Engel, A., Schmidt, U., Volk, C. M., Wetter, T., Levi, I., and Glatzel-Mattheier, $\mathrm{H} .: \mathrm{CO}_{2}$ and $\mathrm{SF}_{6}$ as stratospheric age tracers: consistency and the effect of mesospheric loss, Geophys. Res. Lett., 27, 341-344, 2000.

Stohl, A.: A 1-year Lagrangian "climatology" of airstreams in the Northern Hemisphere troposphere and lowermost stratosphere, J. Geophys. Res., 106, 7263-7280, 2001.

Stohl, A., Bonsanoni, P., Cristofanelli, P., et al.: Stratosphere troposphere exchange: A review, and what we have learned from STACCATO, J. Geophys. Res., 108(D12), 8516, doi:10.1029/2002JD002490, 2003.

Waugh, D. W. and Hall, T. M.: Age of stratospheric air: Theory, observations, and models, Rev. Geophys., 40, 1010, doi:10.1029/2000RG000101, 2002.

Wernli, H. and Bourqui, M.: A Lagrangian 1-year climatology of (deep) cross-tropause exchange in the extratropical Northern Hemisphere, J. Geophys. Res., 107(D2), 4021, doi:10.1029/2001JD000812, 2002. 